

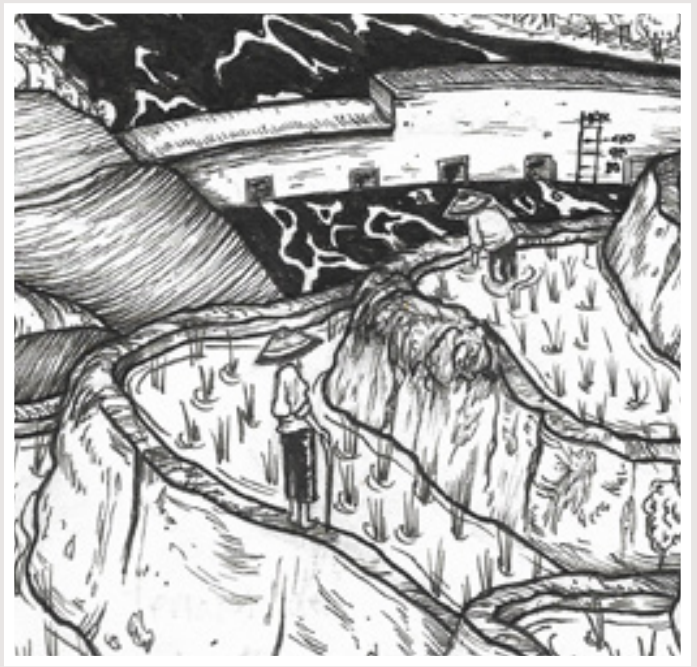

And the old man let his scanty tears dry upon his cheeks and they made salty stains there. And he stooped and took up a handful of the soil and he held it and he muttered: 'If you sell the land, it is the end.'

The Good Earth, Pearl S. Buck 


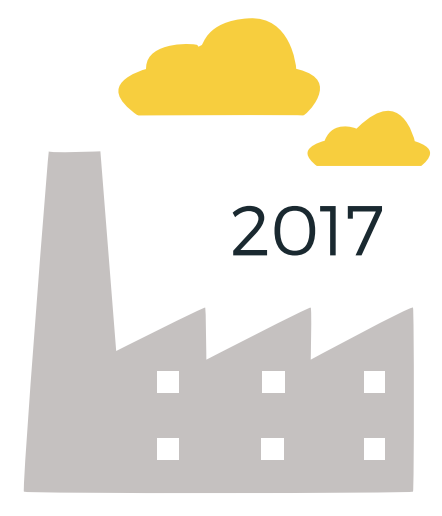

\section{MADE IN}

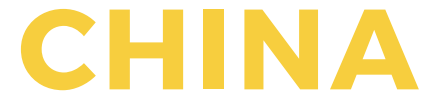

Made in China is a quarterly on Chinese labour, civil society, and rights. This project has been produced with the financial assistance of the Australian Centre on China in the World (CIW), the Australian National University, and the European Union Horizon 2020 research and innovation programme under the Marie SkłodowskaCurie Grant Agreement No 654852. The views expressed are those of the individual authors and do not represent the views of the European Union, CIW, or the institutions to which the authors are affiliated.

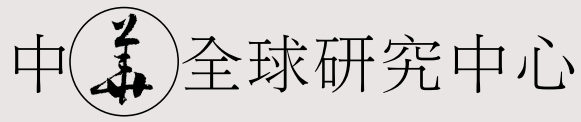

AUSTRALIAN CENTRE ON CHINA IN THE WORLD

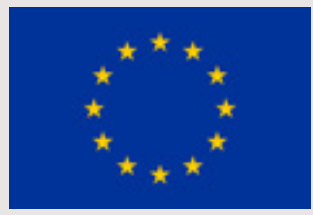

CHINORESIE

mismatched shards of China 


\section{7}

\section{1 \\ a}

VOLUME 2, ISSUE \#2

APRIL-JUNE 2017

ISSN 2206-9119

CHIEF EDITORS

Ivan Franceschini

Nicholas Loubere

GUEST EDITOR

Andrea E. Pia

EDITORIAL BOARD

Kevin Lin

Elisa Nesossi

Christian Sorace

COPY-EDITING

Sharon Strange

ART DIRECTION

Tommaso Facchin

ISSUE CONTRIBUTORS

Maris Boyd Gillette

Chen Shuxia

Fu Hualing

Brendan A. Galipeau

Carlo Inverardi-Ferri

Timothy McLellan

Edwin Schmitt

COVER ILLUSTRATION

Marc Verdugo

PHOTO CREDITS

Andy C (PP.10-11), Flickr

Ren Hang (PP. 50-51), Website

TABLE OF CONTENTS

EDITORIAL (P. 5)

THE GOOD EARTH

\section{BRIEFS (P. 6)}

CHINA COLUMNS (P. 10)

WHAT FUTURE IS THERE

FOR HUMAN RIGHTS

LAWYERING IN CHINA?

(P. 12)

Fu Hualing

SLAVING AWAY (P. 16)

Ivan Franceschini

CHINA'S INDUSTRIAL

HERITAGE WITHOUT

HISTORY (P.22)

Maris Boyd Gillette

FOCUS (P. 26)

INTRODUCING THE CHINESE

COMMONS (P. 28)

Andrea E. Pia

A WATER COMMONS IN

CHINA? (P. 30)

Andrea E. Pia

AMATEURISM AND OUR

COMMON CONCERN FOR

BIODIVERSITY (P. 34)

Timothy McLellan
COMMONS AND THE

RIGHT TO THE CITY IN

CONTEMPORARY CHINA

(P. 38)

Carlo Inverardi-Ferri

BURNING COAL IN

TANGSHAN (P. 42)

Edwin Schmitt

PROTECTING SACRED

COMMONS (P. 46)

Brendan Galipeau

WORK OF ARTS (P. 50)

REN HANG: BODIES

WITHOUT REDEMPTION

(P.50)

Chen Shuxia

ACADEMIC WATCH (P. 54)

CHRISTIAN SORACE ON

SHAKEN AUTHORITY

(P. 58) 


\section{The Good Earth In Search of the Chinese Commons}

In June, the government of the United States announced its intention to withdraw from the Paris Accords, severely undermining the global effort to contain climate change. Since then, China has entered the fray, attempting to portray itself as a world leader on environmental issues. Considering that China is currently the largest emitter of greenhouse gases, this development might appear paradoxical. Nevertheless, in recent years the Chinese authorities have become increasingly concerned with the toll that environmental catastrophes are taking on the health of the country's citizens, as this has the potential to spark unrest that could negatively affect governmental legitimacy. The 'airpocalypses' that have hit major Chinese cities and the 'cancer villages', where disease has spread due to soil and water pollution caused by industries, are just two instances of major environmental scandals that have made the headlines in China over the years. It is in light of this crisis-and also in an attempt to capitalise on environmental protection economically-that the Chinese leadership has been pushing forward ambitious plans for 'environmental rejuvenation', which include new policies and massive investments in renewable energies.

While global attention has focussed on China's top-down environmental efforts, in this issue of Made in China we consider the engagement of Chinese citizens with state policies on the environment, and look into their potential for articulating workable grassroots alternatives. In particular, we examine the management of public resources-the so-called 'commons'. In A Chinese Water Commons?, Andrea Pia argues that there are places in rural China where water is already being managed as a commons. In Amateurism and Our Common Concern for Biodiversity, Timothy McLellan outlines his experience with a project aimed at introducing biologically diverse agroforestry in a county in southwest China, and puts forward a critique of professionalisation in the realm of international environmental cooperation. In Commons and the Right to the City in Contemporary China, Carlo Inverardi-Ferri tells the story of an urban village on the outskirts of Beijing, providing insights into the process of land commodification in today's China. In Burning Coal in Tangshan, Edwin Schmitt traces the history of coal mining in China, highlighting the nexus between the physical characteristics of energy resources and the development of the rules that govern them. Finally, in Protecting Sacred Commons, Brendan Galipeau explores how some Tibetan communities engaging in viticulture in northwest Yunnan province pursue an ecologically friendly agenda meant to protect 'common' Buddhist sacred landscapes.

This issue also includes essays related to labour and civil society. In What Future Is There for Human Rights Lawyering in China?, Fu Hualing analyses the practices of Chinese human rights lawyers and examines the prospects for their survival in Xi Jinping's era. In Slaving Away, Ivan Franceschini looks back at the 'black brick kilns scandal' that took place in China ten years ago and attempts to draw some lessons from those horrific stories of forced labour. In China's Industrial Heritage without History, Maris Boyd Gillette examines the public memory of China's socialist industrial heritage. In our cultural section, Chen Shuxia retraces the life of the late photographer Ren Hang, who committed suicide earlier this year. We conclude by interviewing Christian Sorace about his new book on the 2008 Sichuan Earthquake, Shaken Authority.

This journal is hosted by Chinoiresie.info. If you would like to contribute a piece of writing, please contact us; to receive this journal regularly by email, please subscribe to our mailing list. 


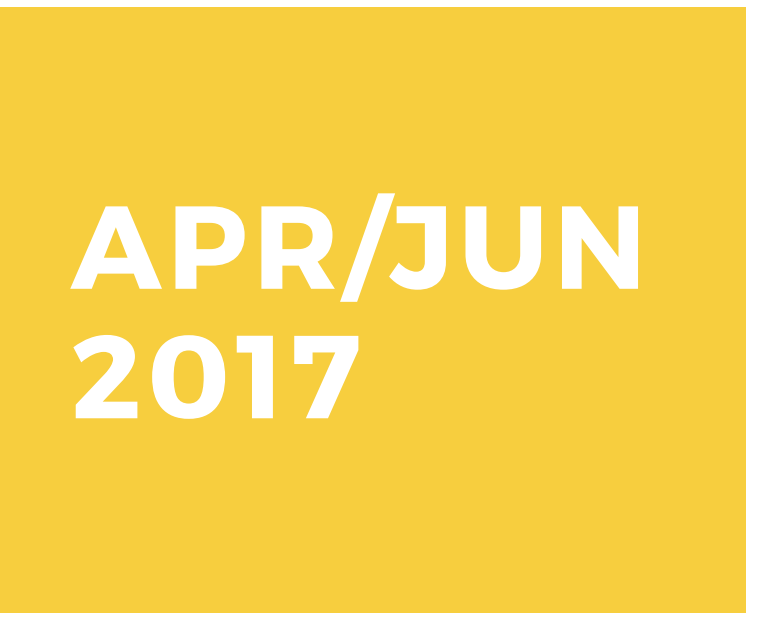

\section{Amnesty International Releases Report on Death Penalty in China}

In April, Amnesty released a report on the death penalty in China entitled 'China's Deadly Secrets'. In spite of the nearly absolute secrecy over the Chinese death penalty system, Amnesty estimates that in 2016 China carried out more executions than all other countries combined. The Report also objects to the unverifiable claims by the Chinese government that the country has been 'killing fewer, killing cautiously' (shaosha shensha). To The Guardian, Amnesty International East Asia Director Nicholas Bequelin explained that without concrete statistics there is no way to verify such claims, and demanded China to 'stop being a rogue state in the international community with respect to the death penalty and finally allow the Chinese people to have a proper, informed debate about capital punishment in the country.' Commenting on the Report for The New York Times, Professor Susan Trevaskes, an expert on the death penalty in China, claimed that the number of people executed annually is probably in the 'low thousands' and that the Chinese government has significantly reduced the use of capital punishment since the mid-2000s. According to the Report, a partial dataset of cases shows that farmers and the unemployed constitute the majority of people given death sentences. $E N$

(Sources: Amnesty International Global Report; Amnesty International China Report; The Guardian; Quartz; The New York Times)

\section{Beijing Offers Rewards for Reporting Spies}

On 10 April, the Beijing State Security Bureau released a set of Measures on Rewards for Citizens Reporting Leads on Espionage Conduct. These regulations promise informants who report on spies rewards ranging between ten thousand and five hundred thousand yuan, depending on the relevance and usefulness of the information provided. The new regulations have been accompanied by the online publication of a cartoon in which a young boy donning the red scarf of a Communist Young Pioneer reports a bearded foreigner wearing a bandit's mask. This is not the first sign of an increasing concern with matters of national security among the Chinese leadership. Back in 2013, President Xi Jinping established a new, secretive National Security Commission of the Communist Party of China in an apparently successful attempt to consolidate the political leadership of all the components of a fragmented security apparatus. In November 2014, the Chinese government passed a Counter-espionage Law, followed a few months later by a National Security Law. In November 2015, Jilin province was the first to introduce a hotline for residents to report possible spies. Since the passing of the National Security Law, the Chinese government has declared 15 April 'National Security Education Day', i.e. a day for raising public awareness of national security issues. In 2016, the day was marked by the appearance of a sixteen-panel cartoon poster entitled 'Dangerous Love' on the public bulletin boards of local governments. This comic told the story of an attractive young Chinese civil servant who meets a redheaded foreign man posing as a visiting scholar and starts a relationship with him, only to find out later that he is a spy. That these concerns remain paramount to the Chinese leadership was also highlighted by the unusually brief round of discussions that preceded the adoption of the new National Intelligence Lawwhich regulates the activities of state security bodies-on 27 June. IF

(Sources: China Law Translate 1; China Law Translate 2; Reuters; The New York Times 1; The New York Times 2; The Paper) 


\section{Salaries of Executives in State-Owned Enterprises Linked to Party-Building Effort}

On 17 April, Premier Li Keqiang told a meeting of top state-owned enterprise (SOE) executives at the State-owned Assets Supervision and Administration Commission in Beijing that the government was reconsidering a 2015 policy capping their pay, and promised more competitive rates tied to performance. According to a Xinhua report, executives' pay and other rewards or punishments will be linked to how well individuals carry out 'Party building' work. This is part of the government's attempt to reform SOE management in order to restructure, modernise, and internationalise the state sector. The latest news is seen as an effort to re-establish the role of the Party in China's state industry, and retain loyal and talented managers. Since 2013, President $\mathrm{Xi}$ Jinping has been pushing for China's state sector-whose worth is estimated at twenty trillion American dollars-to embrace structural reforms while reining in state sector managers' pay. This year, China is about to restart state-enterprise reform, and ten large state-owned enterprises are set to sell stakes in their units. However, the pace of the reform has been slow, and concern over unrest by laid-off state workers has similarly stalled reforms of state-owned steel and coal enterprises (see Kevin Lin's chapter in the Made in China Yearbook 2016). KL

(Sources: Bloomberg; Reuters; South China Morning Post; Xinhua News)

\section{National Bureau of Statistics Releases Annual Report on Migrant Workers}

At the end of April, China's National Bureau of Statistics (NBS) released its latest annual report on Chinese migrant workers. According to NBS, in 2016 there were 281,710,000 migrants in China-1.5 percent more than the previous year. Chinese workers appear to be increasingly reluctant to migrate far away from their hometowns. In 2016, 112,370,000 workers migrated within the boundaries of their town (xiangzhen) of permanent residence-3.4 percent more than the previous year-compared to $169,340,000$ who moved away, an increase of barely 0.3 percent. Significantly, 88.2 percent of the new migrant workers did not leave their towns of permanent residence. Inter-provincial migration is also dropping: 76,660,000 workers migrated to another province in 2016, one percent less than the previous year. These trends are influenced both by the rapid development of the inner provinces, and the policies of the Chinese authorities that encourage migrants to start businesses in their hometowns. Other significant trends include: a) an increase in the percentage of female migrants, who constituted 35.5 percent of the total migrant workforce in 2016; b) the progressive aging of migrant workers, with the average age in 2016 being thirty-nine, 0.4 years older than the previous year; and c) an improvement in the educational level, with the percentage of migrant workers holding a high school diploma-seventeen percent-growing by 1.2 percent. Data related to the protection of labour rights are mixed. In 2016, migrants worked an average of 24.9 days a month and 8.5 hours a day, with 64.4 percent working more than eight hours a day, a decrease of 0.4 percent compared to the previous year. The contractualisation rate was 35.1 percent-1.1 percent less than the previous year. 2,369,000 migrant workers were owed back wages-a drop of 14.1 percent compared to 2015. In general, salaries were still on the rise. In 2016, migrant workers received an average of 3,275 yuanor 203 yuan more than the previous year-a growth rate of 6.6 percent. However, the growth rate for wages slowed by 0.6 percent. $I F$

(Sources: Caixin; National Bureau of Statistics; Sixth Tone) 


\section{Fan Yusu Highlights Plight of Domestic Workers}

In late April, Fan Yusu, a forty-four-year-old female migrant worker from Hubei province, was propelled to literary stardom when her essay entitled 'I am Fan Yusu' went viral. Fan's essay recounts a life marked by patriarchy, domestic abuse, and raising children singlehandedly. She details her feelings of isolation, and the challenges she faced living as a domestic migrant worker in Beijing. Fan also reflects on her experiences of exploitation at the hands of employers, and the unequal treatment she has faced as a migrant due to government policies, stressing the need for solidarity between marginalised and exploited people in contemporary China. In the wake of her success, Fan has been offered book deals and media appearances, but has shunned the spotlight, reportedly leaving Beijing and going into hiding until the unwanted attention has subsided. NL

(Sources: China Digital Times; Los Angeles Review of Books; Sixth Tone; The Paper)

\section{Liu Xiaobo Released on Medical Parole with Late- stage Cancer}

At the end of June, Nobel Peace Prize laureate Liu Xiaobo-who has been serving an elevenyear jail sentence since 2009 for 'inciting state subversion'-was released on medical parole to receive treatment for late-stage cancer. Liu was diagnosed on 23 May, and is now being treated in Liaoning province, despite the requests of his family for him to be treated outside China. Liu's wife Liu Xia-an artist who has been under house arrest since 2010-has said that the cancer is inoperable and untreatable. Liu has been jailed a number of times since the early 1990s for various activities related to human rights and democracy. He was given his current prison sentence due to his involvement in the writing of Charter 08, a document calling for fundamental changes to the governance of China. $N L$

(Sources: BBC; Reuters; South China Morning Post; The Guardian; The New York Times)

\section{Updates on Arrests of Lawyers and Activists}

At the end of April, the ordeal of Li Heping, a prominent lawyer who was caught up in the '709 crackdown' against the weiquan community that took place in July 2015, came to an end. After being detained for almost two years, Li, who is well known to the international community for his overt rights activism, was convicted of 'subversion of state power'. In a secret trial, a court in Tianjin sentenced him to three years in prison with a four-year reprieve, meaning that he was to be released but could still be arrested again at any time. The court ruled that since 2008, Li Heping repeatedly used the Internet and foreign media interviews to discredit and attack China's state power and the legal system. The court also accused Li of accepting foreign funding and employing paid defendants. For many others the ordeal continues. The whereabouts of another lawyer, Wang Quanzhang, remain unknown. Alarming news has also emerged about weiquan lawyer Jiang Tianyong, who disappeared in November 2016 in connection with the Xie Yang's case (see the brief in Made in China 1/2017): reports allege that he was tortured in detention. On 26 May, the Chinese authorities formally announced that Lee Mingcheh, the human rights advocate from Taiwan who had disappeared on arrival to Macau airport in March, was under arrest on a charge of 'subverting state power'. Finally, on 23 June former migrant worker and blogger Lu Yuyu, who was detained in Yunnan province in June 2016 along with his partner Li Tingyu for his work of meticulously recording details of public protests online (see the brief in Made in China 2/2016), stood trial for 'picking quarrels and provoking troubles'. He faces three to five years in jail. Li Tingyu was tried in April and later released without a verdict. $E N$

(Sources: BBC; Hong Kong Free Press; The Guardian; The New York Times; The Wall Street Journal; Weibo) 


\section{Labour Activists Detained While Investigating Ivanka Trump's Manufacturer}

In late May, Hua Haifeng, Su Heng, and Li Zhaothree labour activists working for the New Yorkbased advocacy group China Labor Watch (CLW)were detained by the police in Ganzhou, Jiangxi province, while investigating labour conditions at factories making designer shoes for global brands. In particular, they were inspecting a supplier of Ivanka Trump's fashion brand. Earlier in May, CLW had issued an interim report that alleged forced overtime and a monthly salary of two thousand and five hundred yuan in this factory. The three investigators have been charged on suspicion of illegal eavesdropping, and given limited access to lawyers. According to Li Qiang, the organisation's Executive Director, CLW has been conducting investigations in China for seventeen years, but this is the first time that its investigators have been detained. Ivanka Trump's brand has sought to distance itself from its Chinese supplier. On 5 June, Alicia Edwards, a spokeswoman for the US State Department, declared that the American government is concerned by the arrests, and added that the investigations carried out by Chinese labour activists help American companies to understand conditions in their supply chains in order to hold manufacturers accountable. In response, on 6 June Hua Chunying, spokeswoman for the Chinese Ministry of Foreign Affairs, said that the activists were being investigated on suspicion of using illegal 'professional surveillance equipment.' She added that the case was being dealt with according to the law and that no foreign country had the authority to interfere in China's judicial process. Relatives of the activists have reported being harassed by the public security. On 27 June, the three investigators were released on bail pending trial. $K L$

(Sources: Associated Press; BBC; Bloomberg; The New York Times; The Paper)

\section{Undocumented Chinese Workers Protest in Saipan}

On 22 March, a Chinese construction worker died from a fall at the Imperial Pacific Casino construction site in the American Pacific island of Saipan. Soon after, Federal Bureau of Investigation agents raided the construction site and discovered hundreds of undocumented Chinese construction workers employed by a company named Suzhou Gold Mantis Construction and Decoration. They had been brought to Saipan illegally under a tourist visa programme, after being enticed by the false promises of the labour contractors. In April, United States prosecutors filed criminal charges against individuals connected to the Chinese labour contractors for illegally employing these workers, and the construction projects soon stalled. Investigators also discovered substandard working and living conditions. Out of job since early April, the undocumented workers fought for unpaid wages, staging public protests in front of the casino. On 16 May, over ninety unpaid workers received their salaries and placement fees, and flew back to China. On 1 June, another group of thirty-five Chinese workers staged a protest at the construction site to demand unpaid wages and reimbursement for medical fees for workplace injuries. Again on 22 June, forty-three unpaid workers protested at the same place against unpaid wages. After rejecting an offer of five thousand dollars each from the company, the protesting workers insisted that unless all workers are paid the full wages owed to them, they will not return to China. At the time of publishing, the issue remains unresolved. $K L$

(Sources: Saipan Tribune 1; Saipan Tribune 2; Saipan Tribune 3; The New York Times; The Paper) 


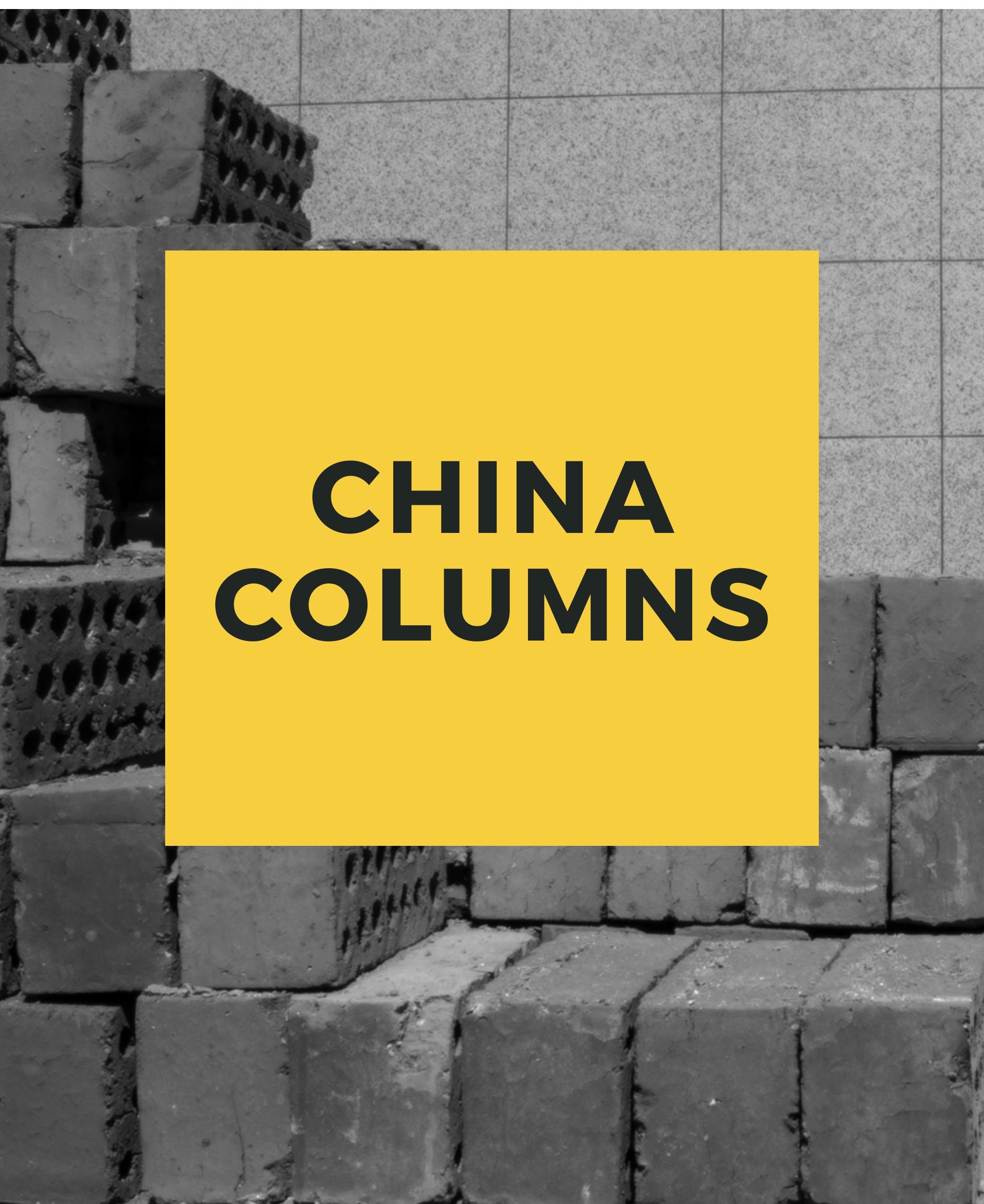




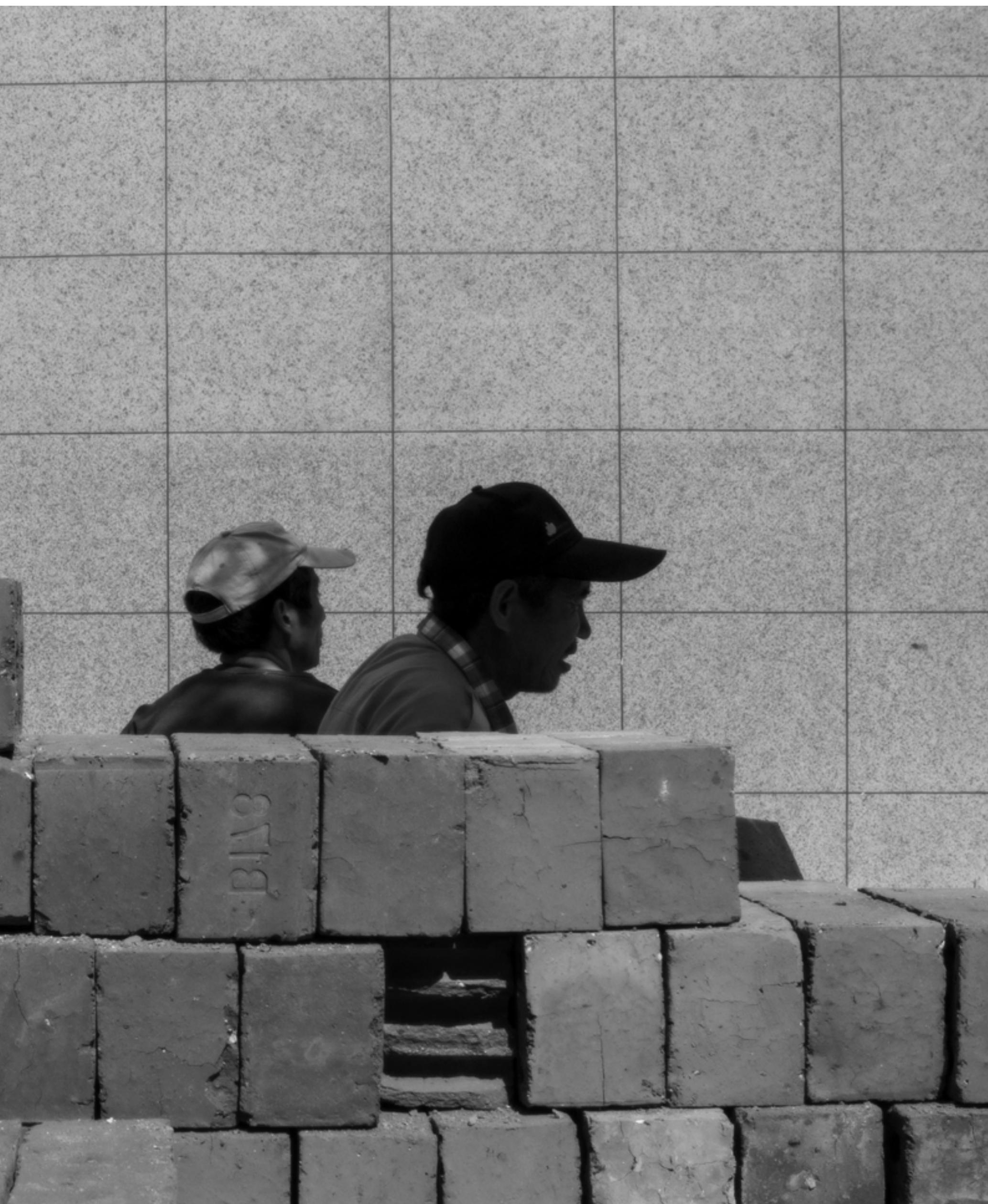




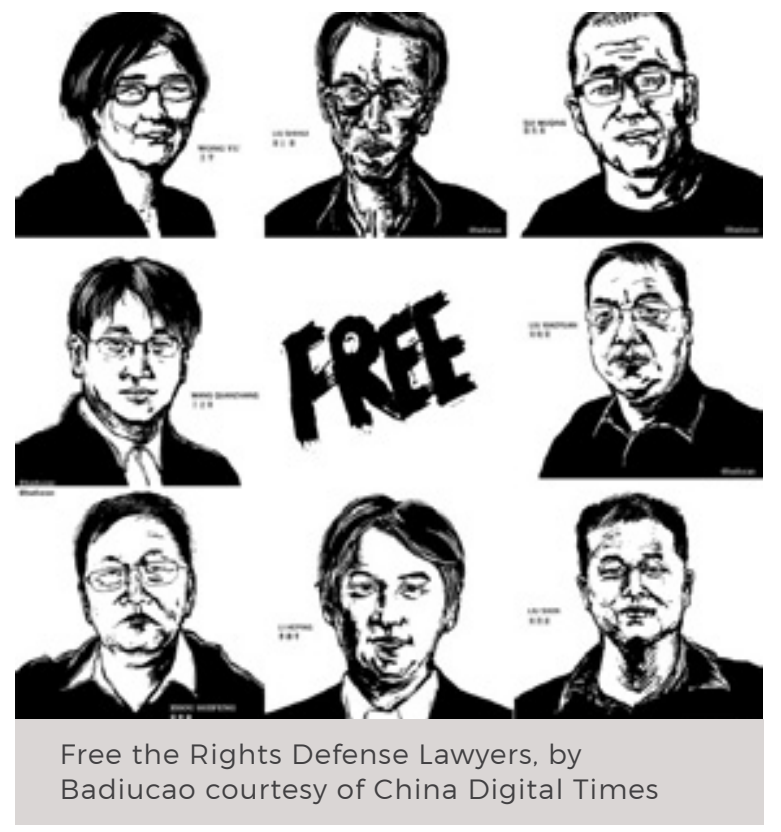

\section{What Future is there for Human Rights Lawyering in China?}

\section{Fu Hualing}

In the aftermath of the latest wave of repression, Chinese human rights lawyers have started to reflect on their past successes and failures. They also began to express anxiety, frustration, and confusion about their work. Ultimately all the soul searching boils down to one question: is there a future for human rights lawyering in China as we know it? To answer this question, this essay analyses the practices of human rights lawyering, and examines the circumstances in which socio-legal mobilisation may fail or succeed.
Eighteen months after the Chinese crackdown on human rights lawyers started on 9 July 2015 (the so-called '709 Crackdown'), a debate took place within the communities of China's human rights lawyers (weiquan lüshi). It was a brief, yet passionate and provocative, discussion on some fundamental questions about the limits of the law in seeking justice and protecting rights in an authoritarian state, and on the limited role that lawyers can play in this endeavour. A pointed question that has been raised is whether the traditional case-focused and law-centred strategy of legal mobilisation, moderate or aggressive, is still a feasible approach to bring structural changes to the political system, incremental or otherwise. In the aftermath of the latest wave of repression, lawyers started to reflect on their past successes and failures, casting doubts on the potential of their own profession in catalysing political transformation. They also began to express deeply-seated anxiety, frustration, and confusion about human rights lawyering. Ultimately all the challenging questions boil down to this: is there a future for human rights lawyering in China as we know it?

This essay addresses this question by analysing the practices of human rights lawyering, and by examining in broad strokes the process through which human rights discourses are translated into practices and the circumstances in which a socio-legal mobilisation may fail or succeed. In particular, the article focuses on the collective and sustained endeavours in which human rights lawyers and other citizen activists advocate the rights of specific communities through a relatively stable organisational structure. The primary concern here is not with the exceptional successes, nor with the notable failures in rights practices manifested in individual cases. Instead, the point is to take a close look at institutionalised routines in which legal cases are used as entry points to mobilise support from popular opinion, and bring those pressures to bear on decision-makers. 


\section{Human Rights Ideas as an External Shock}

To change a stagnant system, an external shock through the challenge of fresh and even 'subversive' ideas is necessary. Most of the human rights ideas, as practiced in China, originated outside of China and were then appropriated by Chinese reformers. Given that China is a late-comer in the construction of its legal system, importation and appropriation of foreign ideas has proved crucial for the seeding, incubation, and growth of rights discourses and practices.

Since legal activism is guided by a moral vision of social change for the better, ideas that are appropriated are often regarded as progressive with some liberating and emancipatory impact. As such, they serve multiple functions. Ideas have an enlightening power: they educate, raise awareness, allow people to look at their world in alternative ways, and, in general, they lift up people's spirit. Ideas also have the instrumental value of empowering people to re-frame their grievances and claims, enabling them to articulate and assert their positions in more effective and forceful ways.

The appropriation of human rights discourses has always been a contentious issue. Some concepts have been quickly accepted and entered the mainstream. Others remain lofty ideas at a philosophic level, but have not been meaningfully put into practice. Yet others have been rejected firmly at an ideological level. In general, to become part of the mainstream, a rights discourse has to be politically acceptable or at least tolerated. In addition, we can say that if a discourse is merely property of the elites or vanguards, and the masses cannot claim ownership and make use of it in their daily life, it will not be effective.

Legal activism is a top-down process in which elite members of a community-and those with visions, resources, and leadership ability-can, in the right circumstances, translate rights discourse into practices that will eventually catalyse a rights movement. China is not short of heroes or heroines in the legal field who have the courage and wisdom to fight alone. But what makes China's rights practice enduring is the alliance making in the rights complex, capacity building in the NGO sectors, and the development of a critical citizenship among stakeholders and constituents.

\section{No Leaders, No Rights Movements}

China's rights movement is closely associated with a small group of individuals who often single-handedly trigger and then lead rights mobilisation in their respective fields. Few would deny the significant contributions that a limited number of individuals have made in organising and leading China's rights practices. No leaders, no rights movements.

Leaders in China's rights movement share many core characteristics. A key quality of an effective rights leader is their credibility among the constituents they seek to represent. Leaders are not only embedded in the communities they work with, but are also able to develop common interests through their advocacy. An idea may be foreign, but organisation must be indigenous, and activism that is resilient and effective must be bottom up and inside out. In that sense, successful leaders are insiders. What is crucial, in the end, is the common identity, developed through frequent interpersonal connections, that binds leaders and constituents. Leaders who are embedded in, part of, and supported by the respective physical and cultural communities are able to make their ideas enter the mainstream, empower and energise communities, and translate their ideas into practice. A shared identity, such as that of 
gender, sex orientation, disability, or social status, generates a strong sense of internal solidarity which, in turn, motivates members to strive for a collective endeavour.

There exist different strategies based on different positioning of the leaders and the demands of their constituents. There are also significant fault lines, which divide rights movements in various subfields. First of all, there is a divide based on agenda setting and prioritisation of issues between elitists who aim at policy change and political impact, and grassroots campaigners who are principally concerned with welfare and short-term interests. Second, there is a fault line between those who focus on individual cases and those who prioritise institutional and structural changes. The main question in this case is whether the limited resources should be spent on addressing some immediate concerns or on raising more structural issues targeting a root cause. Finally, there is differentiation between those who work for and within the system, and those who challenge it. Traditional human rights lawyering is suspicious of legal institutions, and treats courts as adversaries rather than partners to work with and rely on. However, many lawyers insistently rely on the system to achieve larger policy objectives. Instead of challenging or bypassing the courts, there is now a more critical engagement between judges and lawyers in the courtroom, as well as in the court of public opinion.

For instance, the celebrated $\mathrm{Mr}$ Lu Jun, a key leader in China's civil society, argues persistently and forcefully that organisation matters the most in socio-legal activism. By organisation, Lu means coordinated and sustained socio-legal mobilisation that is case-focused and rights-based. This requires the active participation of lawyers, NGOs, and media, aiming simultaneously at influencing the immediate legal decision, shaping public opinion, and lobbying institutions for certain legal and policy changes. Under Lu Jun's leadership, the NGO Yirenping excelled in public interest advocacy, but this was prior to the tightening of space for legal mobilisation and, indeed, Lu himself has become a victim of the crackdown. Can this style of public interest lawyering continue in these new and visibly more hostile circumstances?

\section{Lingering Spaces for Socio-Legal Mobilisation}

While the world's attention is directed to the persecution of lawyers and activists in the wake of the 709 Crackdown, there remains in China a resilient form of socio-legal mobilisation with a sharp focus on equality rights. Yes, there is much less political space for activism and street action, but while this new hostile environment has halted the flash mob type of street action, a courtcentric mobilisation is still feasible. This is a familiar story in which human rights lawyers work closely with the respective NGOs and use litigation as an entry point to shape and influence public opinion with the ultimate goal of achieving certain legal or policy changes.

A key difficulty in launching public interest litigation today is the absence of plaintiffs. Suffering and grievances abound, but victims who are willing to step up to confront their bullies are a rare occurrence. Once a plaintiff is identified and prepped, a campaign has to be designed and implemented. A suitable team of public interest lawyers is retained, law professors in the respective fields are consulted, and journalists are notified. Once a case is in court, the event is widely publicised and circulated in the media-including in official media-whose involvement may have been reduced but has not been prohibited. In these cases, all the parties in the rights arena have a common goal, that is to make the case educational for the general public and a deterrent for offending parties. The media landscape remains a significant battleground for public interest cases. Through a strategy 
of combining legal action through social media mobilisation and civil society capacity building, underpinned by continuous legal reform to strengthen professionalism, lawyers are able to move forward-inch by inch-knowing the potential setbacks and risks that lie ahead.

Without a meaningful political process, legal mobilisation that is case-focused and court-centric is bound to be 'petty'-soft in the approaches taken, incremental in objectives to achieve, and negligible in challenges to pose. Ten years ago, lawyers went to court to challenge discriminatory rules and practices; now the same lawyers have to restart, literally from scratch, similar litigation. Now, however, they have less political space while continuing to experience a similar degree of ignorance, insensitivity, and hostility. Even if they win, as they occasionally do, their actions do little to moderate political power or to hold the repressive arm of the state accountable.

\section{Two Answers to the Challenges Ahead}

Activist lawyers have offered two answers to the challenges. A 'weak' answer relies on remedial justice. That is, while well aware of the structural constraints placed on sociolegal activism, lawyers can still choose to do whatever they are allowed to do in order to make a contribution. As long as there is space-no matter how limited this space isand as long as there are cases-no matter how petty they are-lawyers will continue.

A 'strong' answer points to the fact that public interest law survives a brutal political repression thanks to the resilience and strength of a rebellious sector in the legal profession and in civil society. Public interest litigation is not mainly about winning a case, but is about persuading power holders and educating the general public. Education and persuasion are necessarily slow paced and incremental in their processes. In addition, cases and the battles surrounding them serve as boosters for all stakeholders in the rights complex as, one by one, they strengthen the resolve of the forces of civil society and enhance their capacity in their on-going negotiations with the Party-state.

More specifically and pointedly, individual cases do trigger systemic or structural changes. There are many examples of casedriven changes that have happened in the past. While one can argue that legal advocacy in authoritarian states cannot lead to transformative political change-and that, as some human rights lawyers insist, legal battles in court rooms do not have a democratisation potential-one can argue with equal force that, as long as the regime embraces a degree of legality and promulgates laws to protect a range of legal rights, those rights-friendly laws can be enforced more or less effectively, and rights can be protected more or less rigorously. Legal and political opportunities are there, and it depends on civic leaders, professionals, and civil society at large to seize the opportunities to empower their human agency and to maximise their rights and freedoms through socio-legal action.

\section{Fu Hualing}

Fu Hualing is a Professor in the Faculty of Law at the University of Hong Kong. His research interests include constitutional law and human rights, with a special focus on legal institutions. 


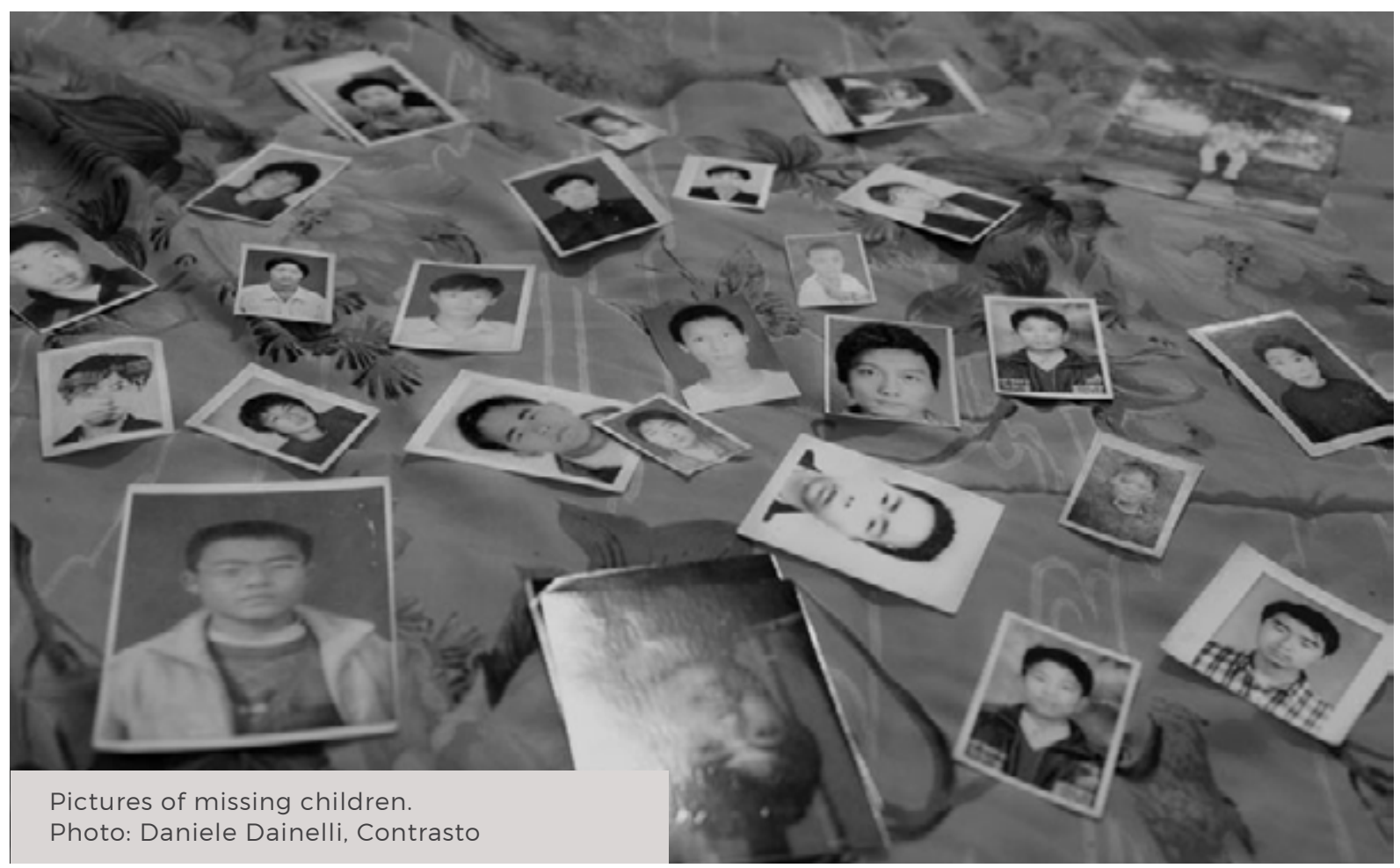

\section{Slaving Away: The 'Black Brick Kilns Scandal' Ten Years On}

\section{Ivan Franceschini}

In the spring and summer of 2007, bands of aggrieved parents roamed the Chinese countryside looking for their missing children, whom they learned had been kidnapped and sold as slaves to illegal kilns. Thanks to the involvement of Chinese media and civil society, the so-called 'black brick kilns incident' became one of the most remarkable stories of popular mobilisation and resistance in contemporary China. Now that ten years have passed, are there any lessons that we can draw from this moment in history?
3,653 days, 3,653 posts. Day after day for ten years, one solitary blogger has been keeping track of the time that has passed since 28 March 2007, when fifteen-year-old Yuan Xueyu disappeared from a construction site in the centre of Zhengzhou, Henan province. Every morning, this blogger-who in his 'ordinary' life is a prominent media personality in China-posts exactly the same message: 'Today it is day $x$ in the search of Yuan Xueyu. Public Security Bureau of Zhengzhou, could you please tell us what progress has been made in his case? The missing workers in the incident of the black brick kilns in Shanxi province remain missing. Netizens have donated four thousand yuan as a reward for any relevant clue. The Public Security Bureau of Zhengzhou opened the case related to Yuan Xueyu's disappearance back in 2007.'

Yuan Xueyu had arrived in Zhengzhou a couple of weeks before his disappearance to be an apprentice to a fellow villager-a worker specialising in setting up window frames. Like many of his childhood friends, he had been unable to resist the call of the big city, 
which resounded particularly strong in his remote rural village, and against the wishes of his father had dropped out of middle school. When he heard that his son was nowhere to be found, Yuan Cheng did not waste any time. He immediately went to Zhengzhou and took up a job in the same construction site. He posted leaflets with the photo of his son everywhere, but the only result was that strangers started to call him pretending to know the boy. Saying that his son had been in an accident, they asked him to wire some money and then disappeared. It was only after encountering other parents whose children had disappeared in similar circumstances, that Yuan Cheng finally found some hope. Listening to their stories, he realised that there was a good chance that his son had been kidnapped and sold into slavery in a brick kiln somewhere in the countryside. The prospects were still dim, but at least now he had an idea where to look.

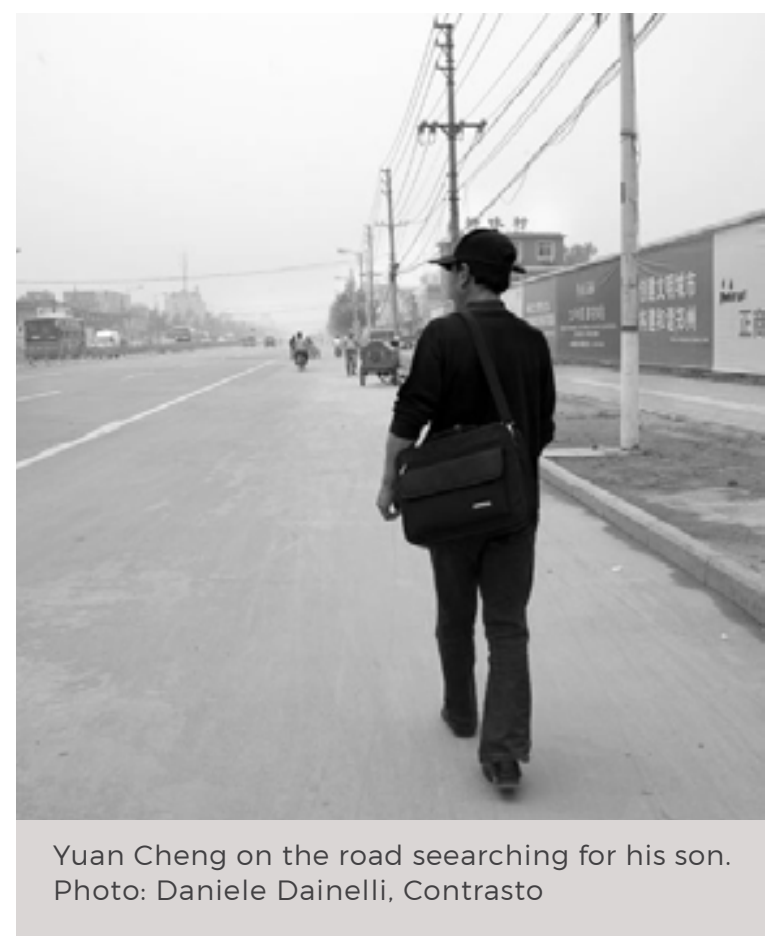

In the spring and summer of 2007-in what came to be known as the black brick kilns incident' (heizhuanyao shijian)-these bands of aggrieved parents roaming the Chinese countryside looking for their missing chil- dren made for one of the most remarkable stories of popular mobilisation and resistance in contemporary China. It was a saga of unendurable pain and unprecedented camaraderie-of friendship as well as betrayal. It was a story that deserved to be told and it quickly piqued my interest and sparked my imagination. I wrote both my first book and one of my earliest media reports on the incident. Instead of focusing on the dark side of slavery and exploitation, I decided to emphasise on the positive side of the mobilisation of Chinese civil society in support of these aggrieved parents. It was indeed an amazing display of solidarity, something that remains awe-inspiring even today. Now that ten years have passed, are there any lessons that we can still draw from this story?

\section{A Mother's Determination}

The chain of events that led to the explosion of interest in the kilns scandal began in March 2007 with Yang Aizhi, a mother whose sixteen-year old son had recently gone missing in Zhengzhou. After covering the city with posters, Yang was contacted by another parent who told her that his two sons had just escaped from slavery in a kiln in Shanxi province. Convinced that her son had to be in a similar place, Yang immediately left for the area. There, she visited no less than one hundred kilns, finding many young slaves, some of them still wearing school uniforms. After going back to Henan, she got in touch with five other parents in the same situation through the missing people announcements published on the pages of a local newspaper. Together, they established what the Chinese media later termed the 'League of the Search for Children' (xunzi lianmeng). In just a couple of months they rescued more than forty children from slavery.

Realising that their task far outweighed their strength, they decided to seek help from the media. As it turned out, their stories were 
so difficult to believe that only one journalist, Fu Zhenzhong of the City Channel (dushi pindao), a local TV station in Henan, accepted to follow them in their search. He made the right choice. When, on the evening of 19 May 2007 , the footage of young boys wearing rags and doing heavy works in kilns in Shanxi that $\mathrm{Fu}$ had shot with a hidden camera was aired on television, there was an uproar. As Fu later recalled, 'in the three days after the airing of the feature about the kilns, about one thousand parents came to the TV station looking for help.' On that day, mothers and fathers that until that moment had not known where to look for their children discovered the existence of the kilns and realised that they were not alone in their plight. It was then that these parents started organising themselves in small teams to scour the Shanxi countryside.

Then, on 6 June, the aunt of a child recently rescued by the League expressed her gratitude in a tearful post on a local web portal in Henan province. This post, which was shared by more than three hundred thousand people all over the country, finally managed to attract the attention of the national media. From that moment on, 'black brick kilns' became a term of common use throughout China.

\section{The Hidden Rules of the Kilns}

For the whole summer of 2007 , the coverage of the scandal on the Chinese media was impressive, with journalists and media outlets competing with each other to describe the reality of the kilns in the smallest detail. Even the Party struggled to keep up with this avalanche of information. It came out that the slaves in the kilns were not only teenagers who had been deceived with the illusion of a well-paid job or abducted with violence, but also adults with mental problems and children, a docile workforce that never raised any demands. Among the lesser-known survivor stories was that of Hao Dingpo, a fifteen-year-old boy who had spent two and a half years in the kilns after being kidnapped from Zhengzhou in March 2005. According to his mother, whom I interviewed back in May 2008, when he finally managed to escape in the summer of 2007 , he had waist-long hair and a number on his wrist. According to his testimony, names were never used in the kiln, only numbers. They had a daily production quota of ten thousands bricks and, when they were not able to fulfil it, they were savagely beaten. When a fugitive was caught attempting to escape, he was beaten to death by the guards and the body was left in the open to rot as a warning to others. Hao Dingpo claimed to have seen six people dying this way, but there was no way to verify his claim as he was never able to indicate the exact location of the kiln.

The conditions in the kilns had a dramatic impact not only on the body of the slaves, but also on their mental well-being. When I met Zhang Shanlin in May 2008, one year after the police had rescued his son from a kiln, he was worried because the boy, who once had been lively and cheerful, had lost any interest in anything, including in his dream of becoming a chef. The teenager refused to leave his house and avoided any human contact. He not only felt ashamed about what had happened to him, but he also kept dreaming about his life in the kiln and woke up screaming almost every night.

The media were relentless in eviscerating the local dynamics behind the existence of the kilns. It was evident that the regime of the kilns could exist only because many people benefitted from it. A Nanfang Zhoumo report quoted a former slave as saying: '[The life in the kiln] was like the food chain in the animal realm... This chain had six rings: the owner of the kiln > the baogongtou [i.e. a subcontractor in charge of all matters related to the workers] > the guards > the older workers $>$ the new workers > the retards.' While the owner was always a local person, the baogongtou 
generally came from somewhere else-usually the place where he found his victims.

The relationship between the black kilns and the local communities was also very important. Although many accounts described the geographical seclusion of these places, local people were well aware of these realities. The reason they accepted them is that the economy of the kilns had its advantages for the local community, since they stimulated local development and created new opportunities to get rich. Support from the local community was also one of the reasons why escaping from the kilns was so hard. Since local workers were too expensive and almost impossible to exploit due to the protection coming from their familial networks, slaves were inevitably 'outsiders' (waidiren). Sometimes local people themselves contributed by supplying the kilns with the workforce they needed. This is what happened to Shen Haijun, a thirty-eight-year-old man from Jiangsu province, who ended up as a slave in a kiln while looking for his mother, a sixty-year-old widow who had been sold as a wife to an old bachelor in Shanxi by a relative. Shen told the journalists that, once he had arrived in the village where his mother had been sold, he had asked an old lady for directions. Under the pretence of helping him find a well-paid job, she sold him to the local kiln owner.

The higher echelons of the Party-state did not fare any better in the media. Reports not only highlighted that the middle-level bureaucracy in Shanxi province was fully aware of the existence of the kilns, but that some officials were even complicit in perpetuating slavery. One of the most unbelievable stories of all was that of $\mathbf{Z h u}$ Guanghui, a young boy from Henan. Rescued by the police from a kiln on 27 April 2007, he was immediately sold back to another kiln by a local labour inspector, who even deducted an intermediation fee' (zhongjiefei) of three hundred yuan from the back salary of the boy. Zhu was rescued again during another police operation at the end of May. In the following days, a local TV station managed to record a confrontation between him and the labour inspector who had sold him. Nobody could have imagined that on that same afternoon the labour inspector would deceive the boy once again, selling him to yet another kiln. Finally, on 18 June 2007, Zhu Guanghui was rescued for a third time and managed to get back home safely.

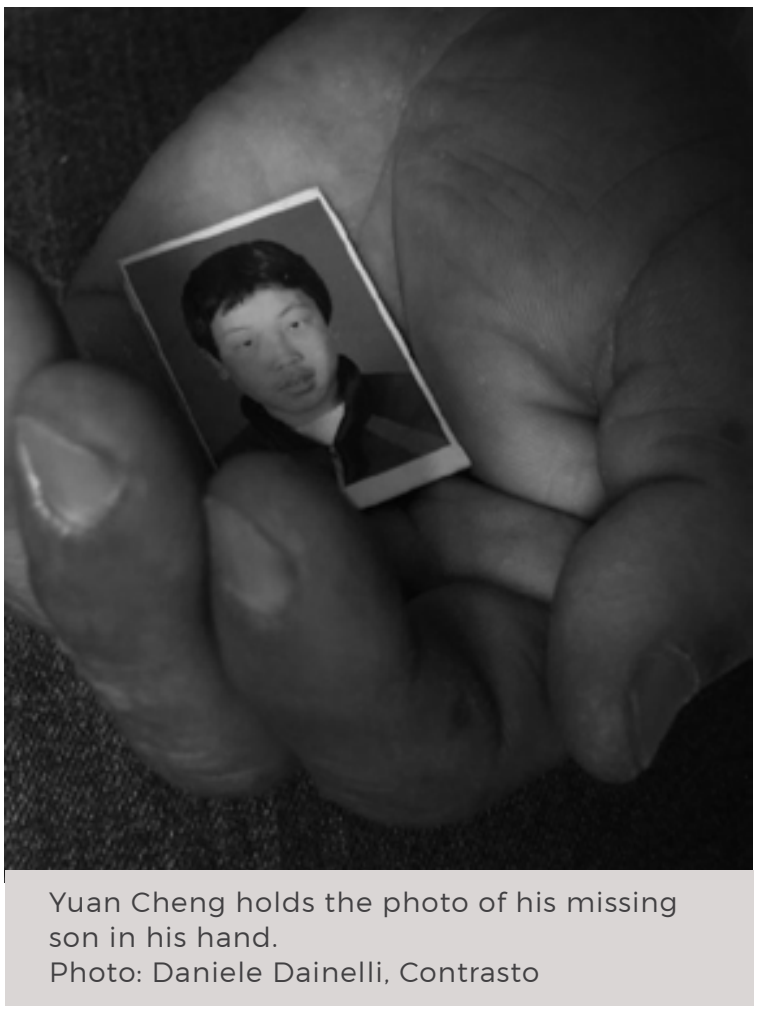

\section{The Response of the Authorities}

The stories told by families of the missing children were filled with desperation and highlighted the indifference of the local authorities. Back in May 2008, Wang Xiaoli, the mother of a boy who had gone missing in 2006 in Gongyi county, Henan province, told me: 'When I went to the police to report that my son was missing, they declined to even open the case. They said that such situations are too common to be taken into consideration.' At the moment of his disappearance, her seventeen-year-old son was studying for the university admissions exam (gaokao). He was one of the best students in his school and 
had a very good chance to be accepted to a top university-a remarkable achievement for a boy from a poor rural area. Yet, on 26 October 2006, he went missing without a trace: he was supposed to spend a few days at a friend's house, but somehow disappeared before reaching his destination.

The media storm triggered by the aggrieved parents changed everything, at least for a few weeks. In June 2007, the central authorities reacted launching a provincial investigation into the Shanxi kilns. The numbers involved were impressive, the outcome less so. According to official data, the police checked 86,395 employers, discovering that 36,286 (forty-two percent) of them were operating without any formal permission; 4,861 brick and tile kilns were inspected, among which 3,186 (63.3 percent) were found to be lacking any registration; in total, the workers in the kilns numbered eighty-one thousand, but only seventeen kilns were found to have severe problems. Among them, thirteen had incidents of child labour. On the whole, 359 workers were rescued, including 121 mentally disabled adults and fifteen children. In the meantime, the top echelons of the Party launched a campaign to 'sweep' the ranks of the local bureaucracy, with ninety-five officials being punished for malfeasance and dereliction of duty, while President Hu Jintao and Prime Minister Wen Jiabao raised their voices asking for further investigations to reveal cases of corruption related to the kilns.

At the same time, the Chinese leadership could not miss the opportunity to ride the publicity wave of the scandal to promote its political agenda. In particular, the media coverage of the kilns was used to accelerate the troubled legislative process that led to the passage of the Labour Contract Law, then stranded due to the emergence of a heated public debate about the advisability of introducing new guarantees for workers' rights at a stage in which economic development was still fuelled by low labour costs. After more than three years of top- level discussions and more than a dozen blueprints, the kilns scandal was an essential factor that facilitated the ultimate approval of the Law, which was passed at the end of June right in the middle of the media storm. Xie Liangming, then Deputy Director of the Department of Legal Affairs of the All-China Federation of Trade Unions, declared: "[If the kilns scandal had not happened] I think that the debate would have continued. Since the scandal deeply moved the legislative bodies, including many committee members who felt that such situations could not be understood and that it was necessary to be more severe, the Law was pushed through.'

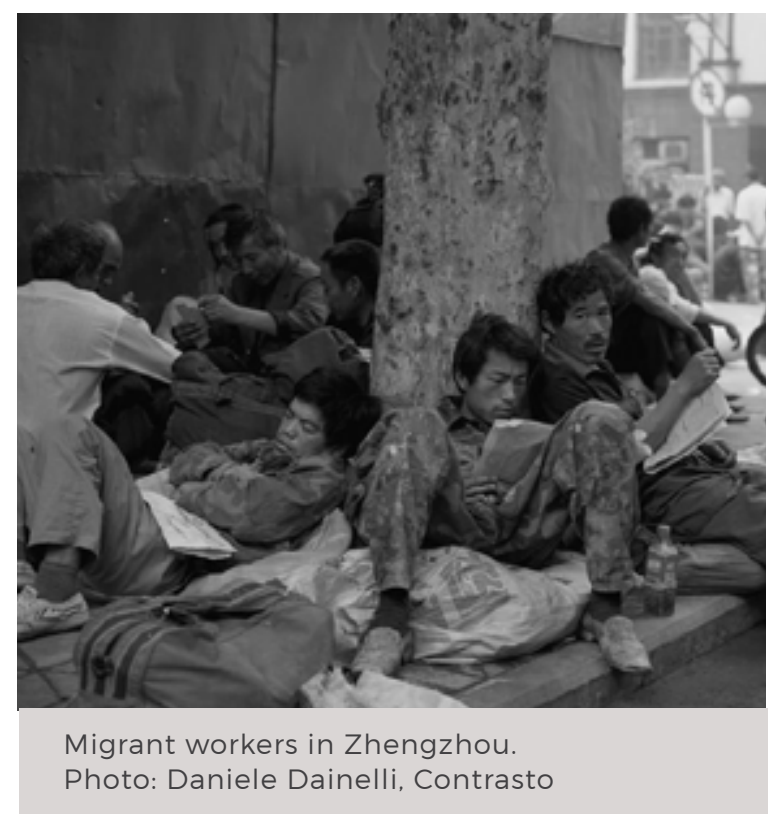

\section{The Kilns After the Kilns}

Ten years later, the kilns might not be as widespread as before, but all the signs point to their continued existence. In May 2009, Chinese media reported that in Jieshou city, Anhui province, the police rescued thirtytwo mentally disabled workers enslaved in two different kilns. According to the available accounts, these people were deceived by a human trafficker, in this case a taxi driver, who earned two to three hundred yuan for 
every person that he 'introduced' to the kilns. Closely guarded by thugs who did not hesitate to resort to violence, these slaves, whose age varied from twenty-five to forty-five, lived locked in a courtyard and were forced to work ten hours a day without receiving any wage besides a few yuan for their personal expenses. The police then arrested ten people, including the baogongtou and the owners.

In June 2010, Chinese media reported that the police in Shilin county, Yunnan province, had rescued about twenty slaves from a local kiln. One of the slaves, a man from Chongqing, described to the journalists the brutality of his guards who, in order to make him work seventeen hours a day, beat him with steel bars and leather belts. Similarly, in December 2010, a story of human trafficking of individuals with disabilities based in $\mathrm{Qu}$ county, Sichuan province, was widely reported in the Chinese media. In that case, everything was happening with the open connivance of the local authorities, under the cover of a public shelter for disabled people. In another remarkable story, in September 2011 Cui Songwang, a reporter for a Zhengzhou television station, hung around a train station posing as a disabled man for two days, until he was kidnapped and sold to a kiln manager for five hundred yuan. Cui said he was forced to work for three hours, beaten and deprived of water before he managed to escape and report the case to police. More recent media reports tell the story of slaves who managed to escape from the kilns, such as forty-threeyear old Xu Shuhe, who was a slave in black brick kilns in Guangzhou for twenty-four years; thirty-three-year old Fan Debao, who spent eleven years in slavery; and thirty-fiveyear old Qi Zhaojun, who was deprived of his liberty for twenty-one years in a number of kilns in Shanxi province.

Yuan Xueyu is still missing, another victim of what Børge Bakken has called China's 'uncivil society'. His father Yuan Cheng is still looking for him and in his search has, thus far, been able to save more than one hundred children. In all this, is there any lesson that can be drawn from what happened ten years ago? Looking at the latest developments in Xi Jinping's China-the taming of the critical voices in traditional and new media, the arrests and disappearances of those who speak for the weak and disenfranchised, the systematic intimidation of those who challenge the message of 'harmony' espoused by the Chinese Communist Party-one cannot but wonder whether a display of solidarity like the one that took place during that hot summer of ten years ago would still be possible today. However, the solitary blogger's daily post is a reminder that not everything is lost, that not everybody has forgotten. In the end, as they say, no matter how hard you try, paper cannot wrap up embers.

\section{Ivan Franceschini}

Ivan Franceschini is a Marie Curie Fellow at Ca' Foscari University of Venice and at the Australian Centre on China in the World. He is working on a project on Chinese labour in a global perspective. 


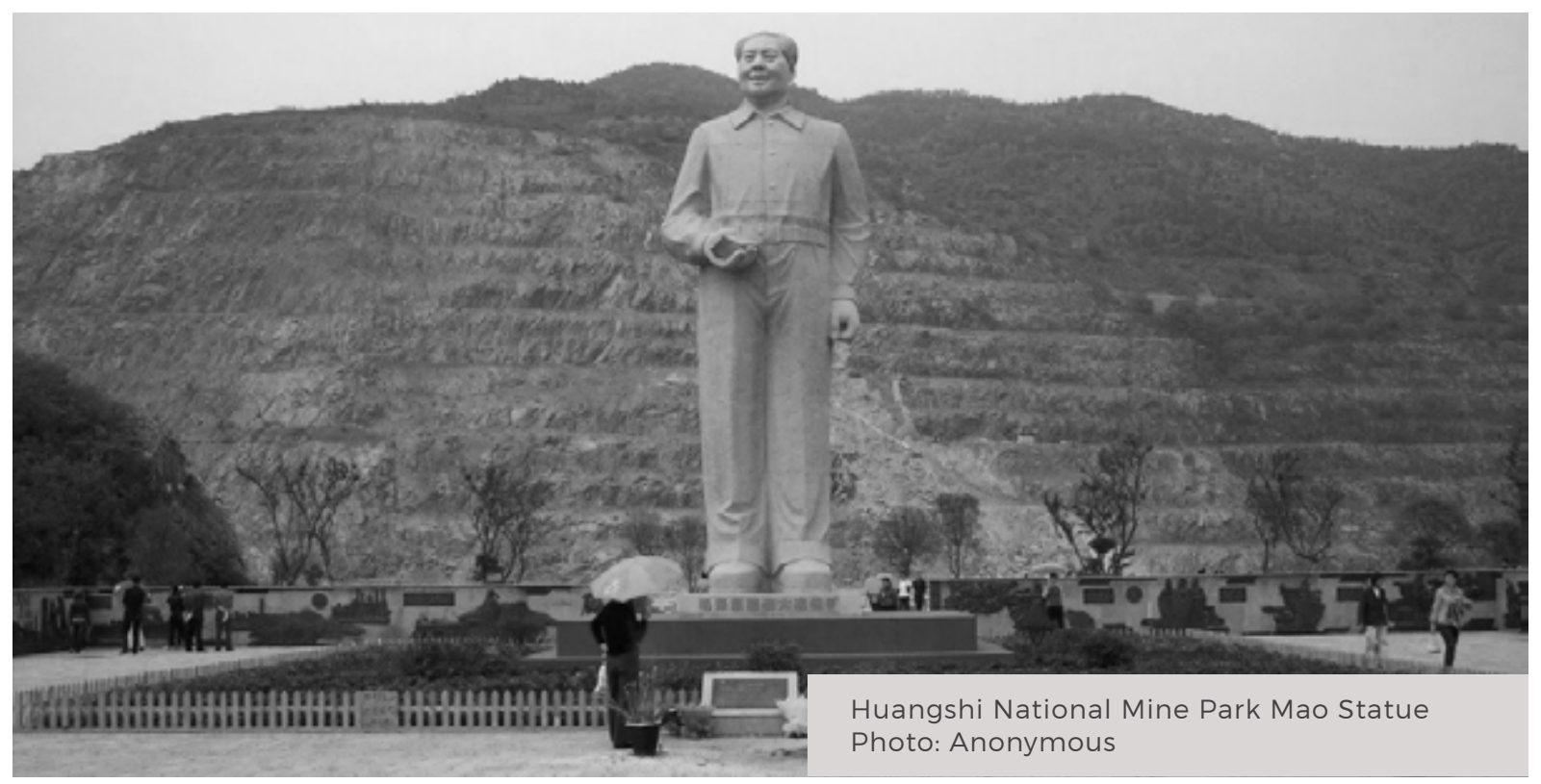

\section{China's Industrial Heritage without History}

\section{Maris Boyd Gillette}

Twenty years after the Chinese authorities decided to radically reform the country's state industry, where does public memory of the nation's socialist industrialisation reside? What aspects of the socialist path to modernity do officials or private citizens monumentalise, if any at all? To what extent does China's contemporary heritage movement encompass its socialist industrial history? This essay offers an initial attempt to answer such questions.
In the late 1990s, thousands of factories across the People's Republic of China (PRC) closed down. Most had been created as part of the Chinese Communist Party's (CCP) programme to industrialise the nation after 1949. Tens of millions of workers lost their jobs, and idle plants pockmarked thirty percent of the urban core of most cities. In Jingdezhen, the city that I have been studying since 2003, state and collective sector workers constituted ninety-four percent of the total employed population when these 'structural reforms' began, and the city contained approximately two hundred state and collective enterprises. The closures and mass layoffs profoundly shocked local residents, who experienced the 'death' of the city's porcelain factories as happening 'almost overnight'.

When China's Communist leadership decided to privatise the state and collective sector, the nation took a final step away from its socialist path to modernity. From the 1950s through to the early 1990s, the central government invested massive sums in industrial development-building new plants, inventing and purchasing new technologies, expanding the workforce, and manufacturing new products. In Jingdezhen, ceramics 
manufacturing grew from one thousand workers doing handicraft production in eight operating wood-burning kilns in 1948, into a massive porcelain industry employing over one hundred and fifty thousand workers in fifty-two mechanised sites, covering all aspects of the production process from mining to finished wares. While some outside observers and Chinese citizens recall this period primarily in terms of its political campaigns, the central government's policies nevertheless shrank income disparities between the countryside and city, provided high levels of employment and extensive job and social security, increased women's participation in the paid workforce, and raised educational levels. The decision to allow the market to drive industrial development was also a decision to relinquish most of the goals that characterised a socialist vision of the future.

Twenty years after the PRC committed China's industrial sector to the path of neoliberal capitalism, where does public memory of the nation's socialist industrialisation reside? What aspects of the socialist path to modernity do officials or private citizens monumentalise, if any at all? To what extent does China's contemporary heritage movement encompass its socialist industrial history? I offer here a first attempt to answer such questions, drawing on published sources and my fieldwork in Jingdezhen.

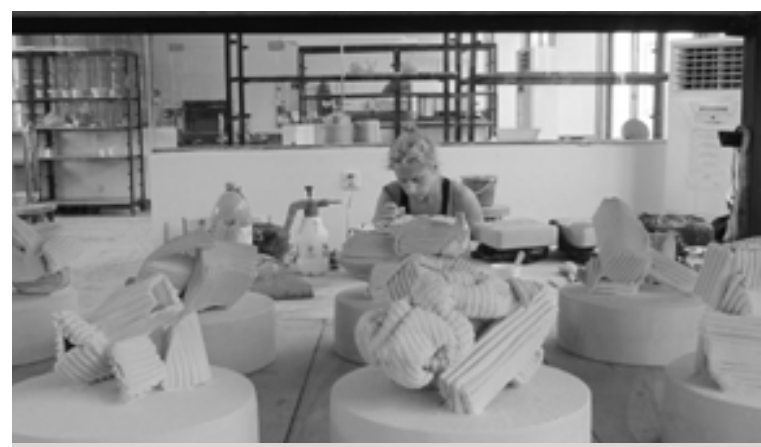

A University of Melbourne ceramic artist doing a residency at the Jingdezhen Pottery Workshop, located in a rehabbed portion of the former large collective Sculpture Factory.

\section{Preserving Memories of Socialist Industrialisation}

Laid-off workers' narratives are the richest repository of public memory about socialist industrialisation. Former state and collective workers have repeated their stories to journalists, documentary filmmakers, and scholars-not only at the time that the state and collective sector collapsed, but for more than a decade afterwards. In their accounts, laid-off workers testify to the meaningfulness of their membership in the socialist work unit (danwei) system in material and psychological terms. They reveal their sense of betrayal and injustice that 'the promises of the socialist ideal simply vanished.' Numerous testimonies show former state and collective employees' insistent identification of themselves as 'laidoff workers' (xiagang gongren), even when they have found other work. By retaining this label, these citizens make a claim to the socialist path of modernity despite the government's rejection of it.

A more superficial form of socialist industrial history resides in the former state and collective enterprise buildings that have been preserved and adapted for new purposes. This type of architectural preservation can be said to have begun in the mid- to late 1990s, when artists in Beijing and Shanghai rented abandoned factories and warehouses to use as studios. In Beijing, some artists who had been evicted from the area around the old Summer Palace in 1995 moved to Dashanzi, a state enterprise built in the 1950s that was once Asia's largest military electronics plant. Factory 798 became particularly well known as an artists' community, so much so that international art galleries and fashionable boutiques turned the site into an 'art theme park' by the mid-2000s. In 2006, the State Administration of Cultural Heritage of China published its first official documents promoting the preservation and reuse of 
industrial heritage. After this, Beijing's municipal authorities began offering funding for private developers.

In Shanghai, private efforts to adapt socialist architecture received government support earlier than in Beijing, partly because the city had already begun preserving its semi-colonial industrial heritage in the early 1990s. One significant early development of a former socialist enterprise was the Chunming Roving Factory on Suzhou Creek. The Shanghai municipal government began redevelopment efforts here in 1992, spurred in part by water pollution. In 1997, Taiwanese architect Teng Kun Yen rented or purchased a Suzhou Creek warehouse built in the 1930s and made it into a design studio. His redevelopment sparked other artists and designers to undertake similar renovations, leading to the preservation and adaptive reuse of not only the Chunming Roving Factory but also the socialist factories on Taikang Road that became known as Tianzifang. Shanghai municipal government officials quickly recognised the potential of rehabilitated socialist architecture to enhance city branding and generate revenue. In 2004, they established a policy to promote 'creative industry clusters' which included tax concessions, special funding, and the ability to redevelop industrial land without applying for formal re-designation. As a result, dozens of socialist industrial sites were repurposed as creative industry clusters.

\section{A Bulldozer Approach}

Other cities were less inclined to abandon what Yung, Chan, and Xu call the 'bulldozer approach' to urban planning. In a 2016 study of twenty cities that received significant state investment for industrialisation during the 1950s and 1960s, Yang shows that most municipal governments have not seen industrial heritage as a marketable resource for redevelopment and have instead removed remnants of China's socialist past. In Jingdezhen, the bulldozer approach to urban planning began in 2000, when the Bureau of Industry and Commerce bought the Jingxing Porcelain Factory, demolished it, and turned the area into a fruit and vegetable market. Other sites of socialist industry were torn down and replaced with retail storefronts and apartments.

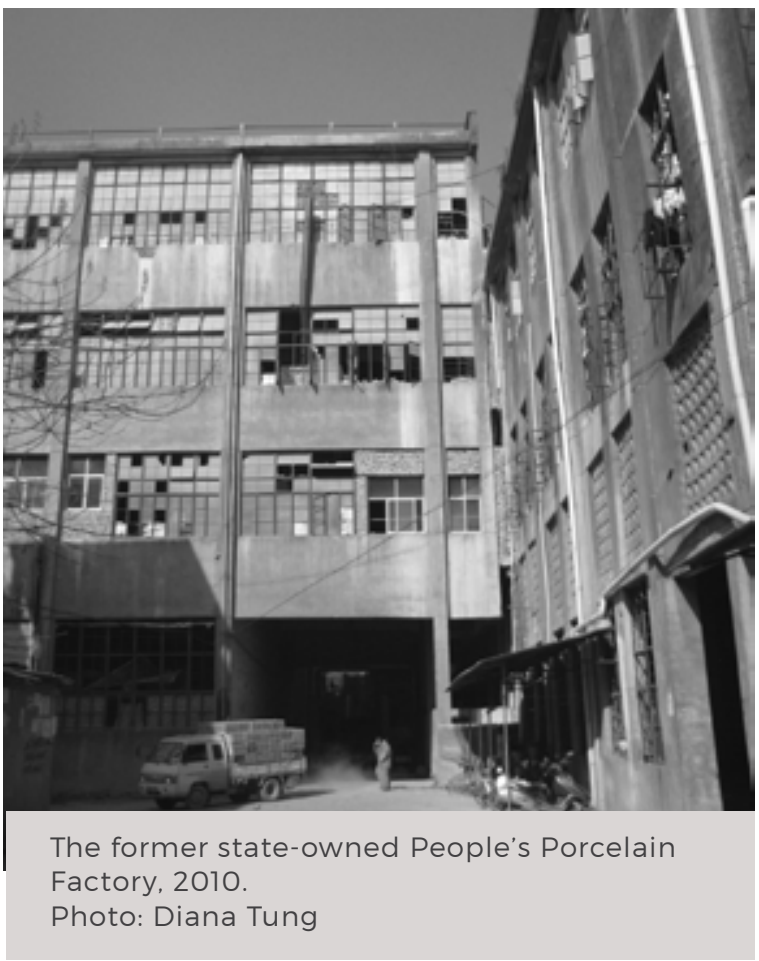

The former 'large collective' (dajiti) Sculpture Factory is Jingdezhen's primary example of adaptive reuse from the socialist period. While portions of today's Sculpture Factory bear no resemblance to the enterprise that was built in 1956, other parts have been preserved and adapted to serve the visiting artists and designers who participate in residencies at Carolyn Cheng's Pottery Workshop. Cheng established her Jingdezhen branch of the Pottery Workshop in the Sculpture Factory in 2005. The facility now houses gallery space, an education centre, a café, and a shop, in addition to spaces where visiting artists can design and create ceramic works. 


\section{Mine Parks}

Mine parks are a third type of site that holds memories of socialist industrialisation. In 2009, the China Mining Task Force announced the government's decision to establish national mine parks at the AsiaPacific Economic Cooperation Meeting. Seven years later, officials reported that China had created seventy-two national mine parks. Among them were the Jinhuagong Coal Mine Park in northern Shanxi, the Huangshi Coal Mine Park in Hubei, the Wanshan Mercury Mine Park in Guizhou, and the Haizhou Coal Mine in Liaoning. While some of the mines were put to use prior to the founding of the PRC, all received significant state resources and saw major resource extraction through to the end of the twentieth century. These 'parks' can include mine shafts, heavy machinery, historic photographs, socialist and contemporary art, and exhibits that describe the history of resource extraction and the 'lifestyles of mining communities'.

Researchers have just begun to investigate these new industrial heritage sites, with published masters theses from urban planning and architecture programmes. A glimpse of how China's mine parks communicate the socialist vision of modernity is available from the reviews of visitors on Trip Advisor. Many describe the former mines as visually spectacular and educational. For some, the sites produce powerful experiences of identification with the former mine workers, a visceral sense of the forward pace of socialist modernisation (jianzhengle xiandai gongye fazhang qianjinde jiaobu), and an awareness of the economic decline suffered by cities dependent on extractible resources (ganjue zhege difang gen henduo ziyuankujie chengshi yiyang, you muoluo de ganjue).

\section{A Façade of Socialist Modernity}

China's socialist industrial heritage is underdeveloped relative to its imperial and colonial pasts. Potential economic gains from tourism and commerce have driven the efforts made to date, which are almost exclusively focused on the built environment. For example, only two percent of China's cultural relics relate to industry. Since at least some of these eighty-three artefacts are from industry prior to 1949, the officially-recognised cultural relics of socialist industrialisation represent an even smaller percentage of the total. At present, China's restored socialist structures and their creative class inhabitants preserve merely the façade of socialist modernity. Today's trendy new users largely overshadow the history of these sites' industrial development and their rapid decline. The PRC has not yet created a national inventory of its socialist industrial heritage. Nor have authorities announced plans to collect oral histories of socialist modernisation. If such trends continue, what remains of the path that China travelled toward socialist modernity will vanish, leaving only a thin veneer of industrial heritage without its rich and colourful history.

\section{Maris Boyd Gillette}

Maris Boyd Gillette is a sociocultural anthropologist and filmmaker who has studied porcelain workers and entrepreneurs in Jingdezhen, as well as urban Chinese Muslims in Xi'an. She works regularly with museums on exhibitions-most recently the Campbell House Museum, the St Louis Art Museum, and the Missouri History Museum. 
Nal 제는 I.

1. 140

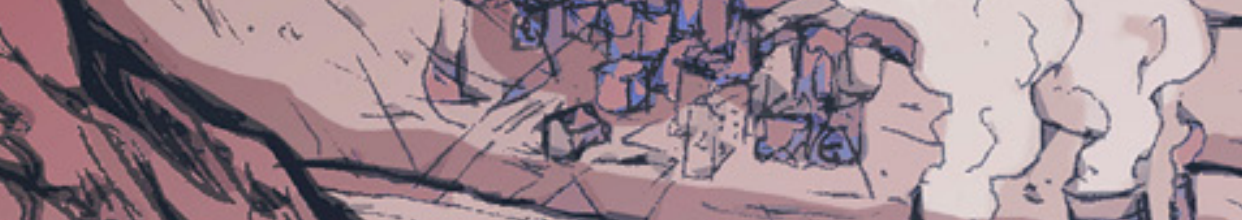

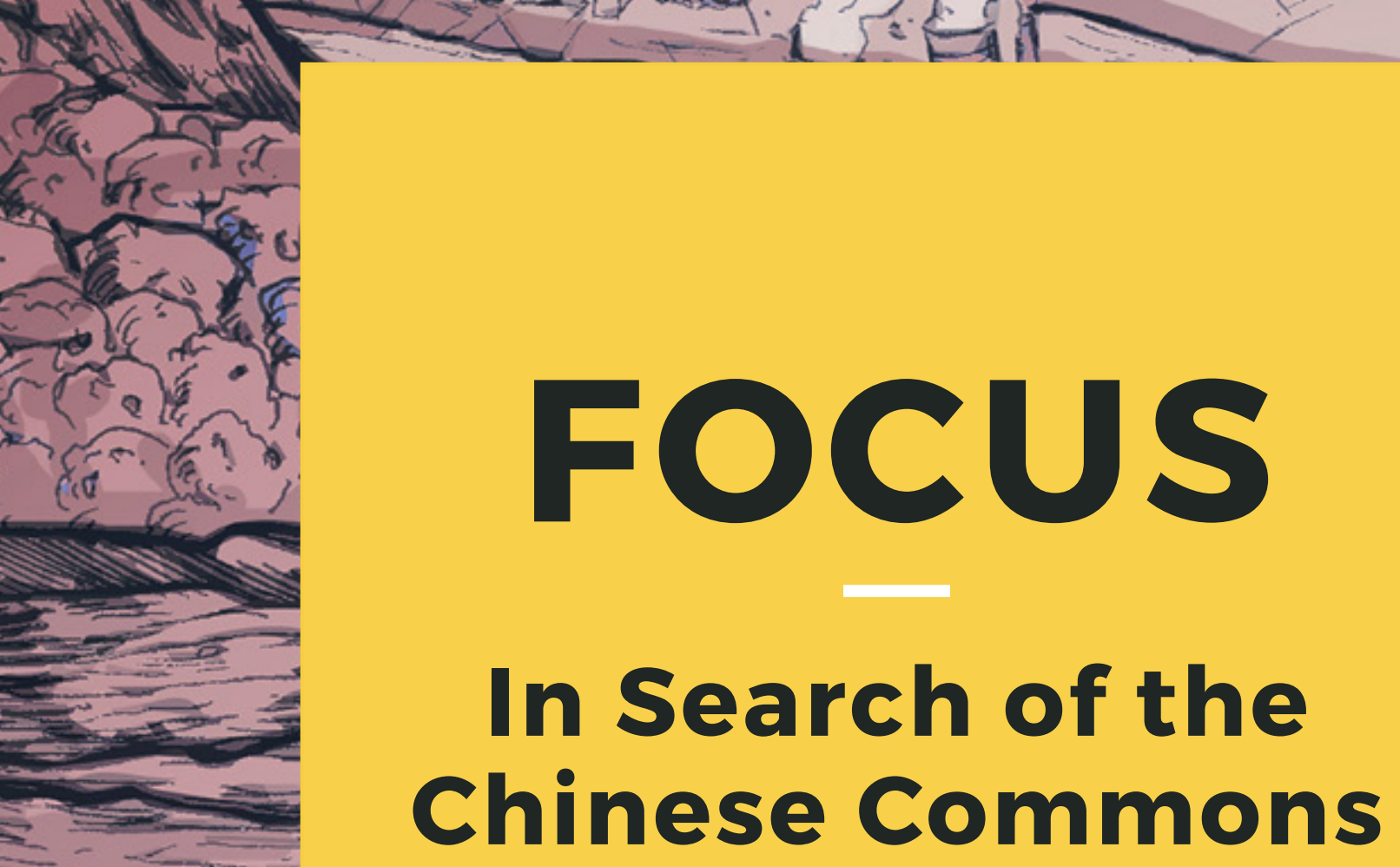

sers

$x+\frac{1}{1}$

In Search of the Chinese Commons

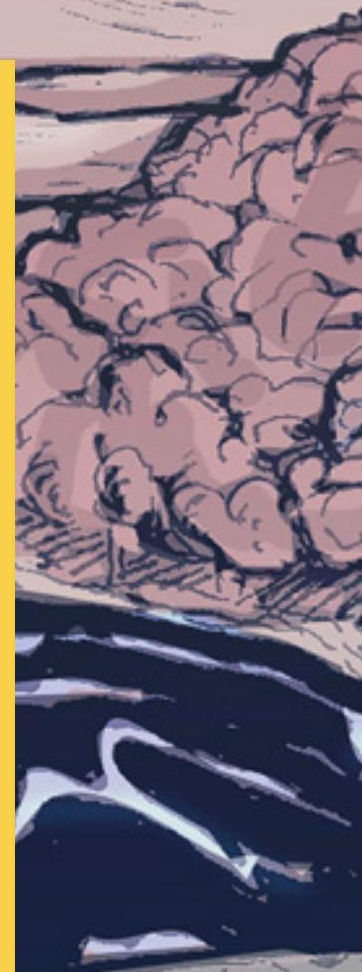

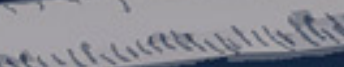

$=$

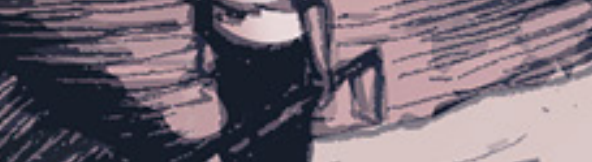

litio d) 2
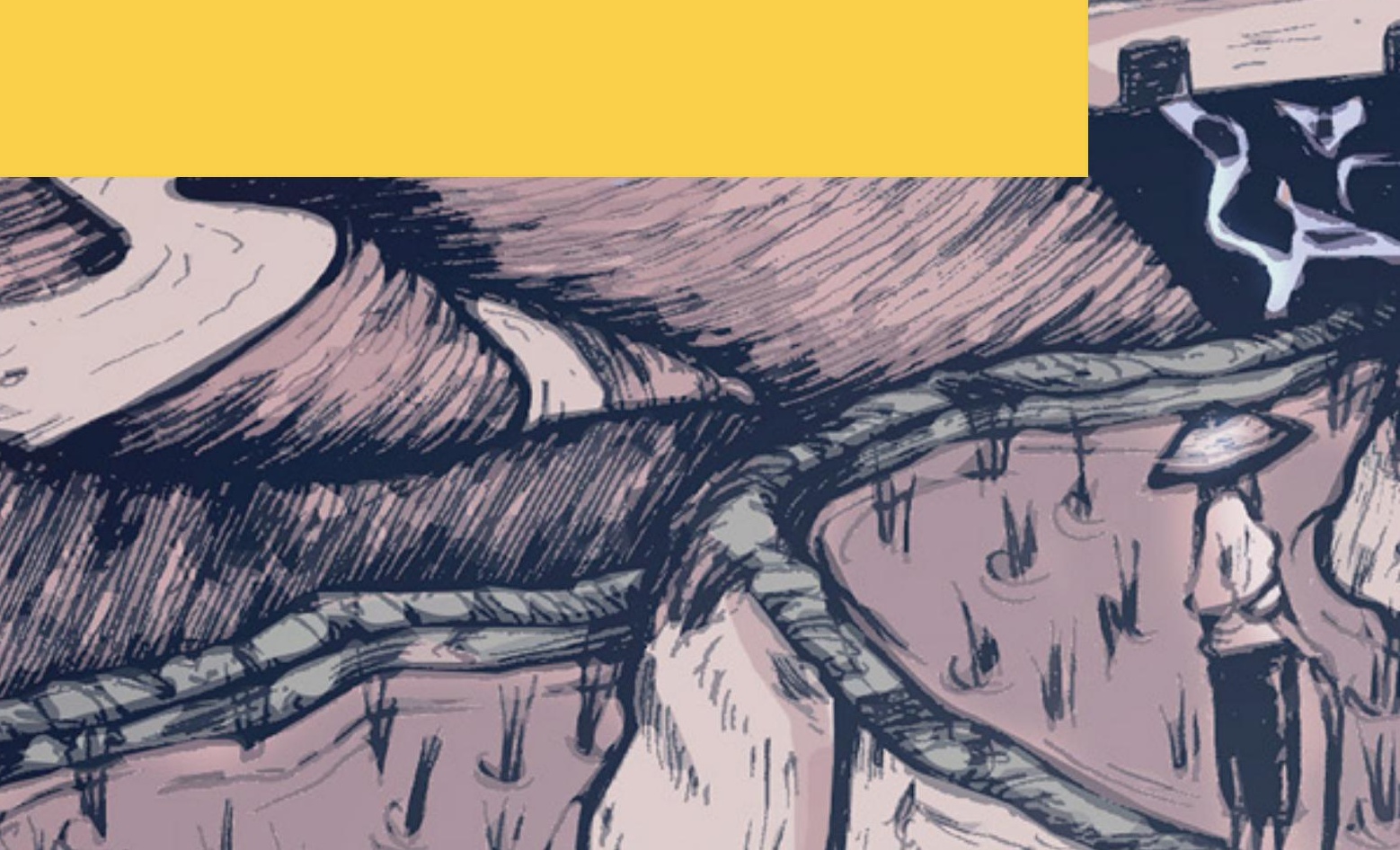

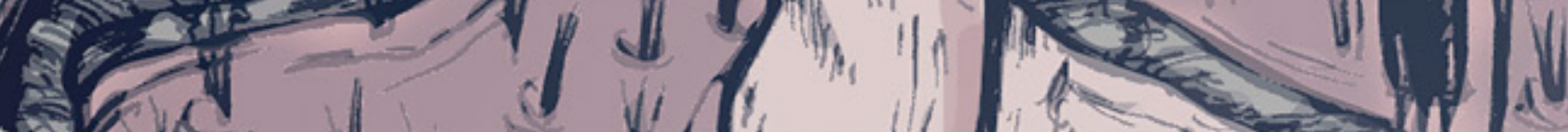




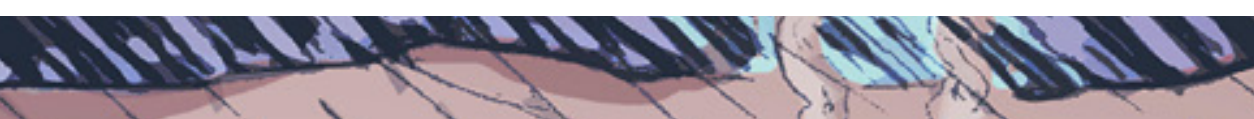

(a)

If $\rightarrow 2+2$

ath s.

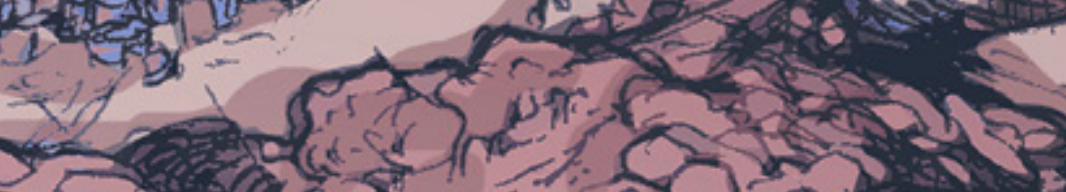

$2 x$

5. 2 a

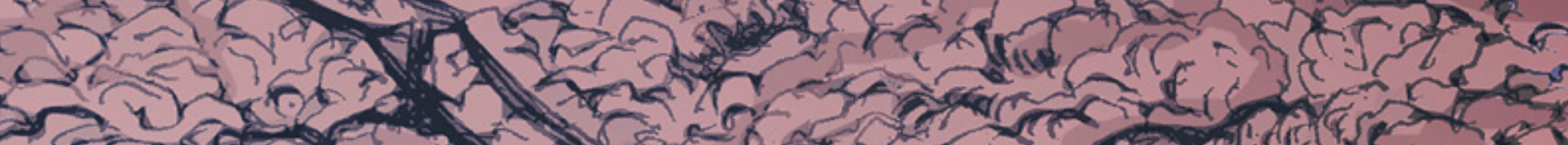

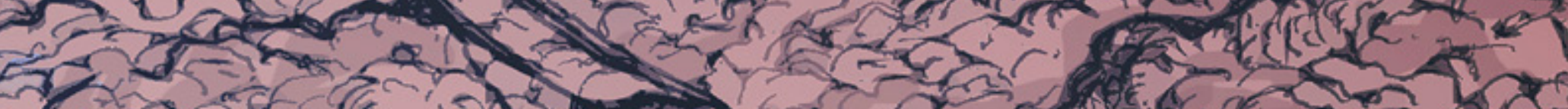

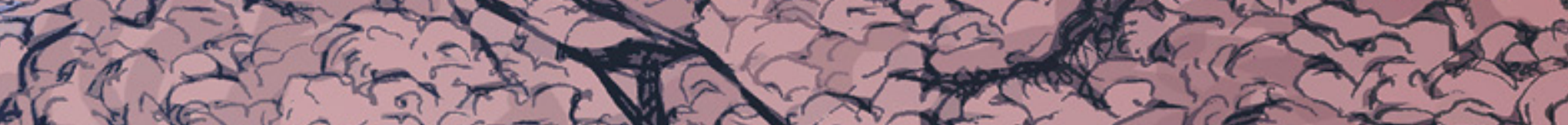

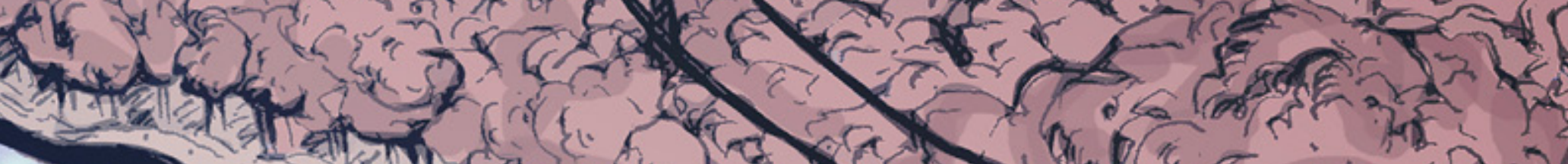

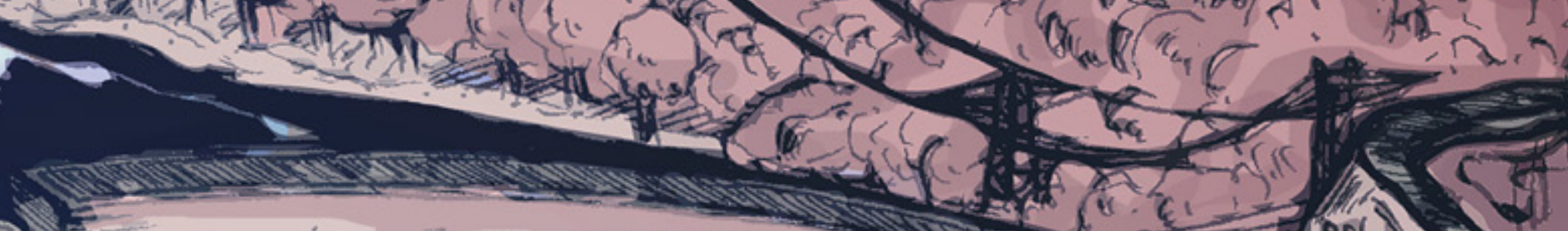

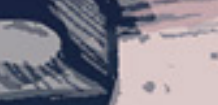

\section{tion \\ 1. 0 -}

$\pi$ c (U) wrom $\mathrm{N}$. Xx.

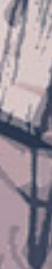




\section{Introducing the Chinese Commons}

\section{Andrea E. Pia}

'[China's] environment can no longer keep pace. Acid rain is falling on one third of China's territory, half of the water in our seven largest rivers is completely useless, while one fourth of our citizens do not have access to clean drinking water. One third of the urban population is breathing polluted air, and less than twenty percent of the rubbish in cities is treated and processed in an environmentally sustainable manner. Finally, five of the ten most polluted cities worldwide are in China.' This is an interview that Pan Yue-a former vice-minister of the Chinese Ministry of Environmental Protection (huanjing baohubu)-gave in 2005. During his time in office, Pan Yue introduced many radical ideas about possible solutions for China's environmental issues, including a proposal for more democratic control over environmental policy-making. Interestingly, the Chinese authorities have now embraced some of Pan's ideas as part of a national policy effort that goes under the name of 'Ecological Civilisation' (shengtai wenming). Ecological Civilisation stems from the recognition that any possibility for the reversal of the country's ecological decline must come from an overall rethinking of its development strategies. Practically, the Central Committee of the Chinese Communist Party has, thus far, supported the establishment of an ecological compensation mechanism, supplementing GDP measurements with quality indicators that take into account environmental issues.

Pundits and government spokespersons are telling environmentalists worldwide to rejoice for what has been hailed as a veritable change of paradigm in China's model of economic growth, from the plundering of natural resources to the rejuvenation of the country's environment. And yet, despite the growing number of official statements and guidelines released by the Central Committee since 2013, there are those who fear that such suggestions will not go far enough in addressing the global magnitude and consequences of China's ecological decline.

If anything, the situation in China has gotten even worse since Pan's interview. According to the available data, almost twenty percent of China's agricultural land is now contaminated, while sixty percent of China's underground water supplies are said to be polluted. Drinking water in most of the country's rural areas is unfit for human consumption because of pollution from fertilisers, pesticides, and industrial activity. Meanwhile worsening air quality has resulted in China taking the top spot in the world rankings for deadliest outdoor air pollution. Crucially, many of China's current environmental issues seem to originate from the state's apparent inability to manage, on its own terms, the manifold dimensions of the country's ecological crisis. Desertification is expanding on an average of one thousand and five hundred square miles per year, in part because of ill-conceived and counterproductive governmental attempts at stopping soil erosion through reforestation. Sustainable grassland management in Tibet deteriorates as China implements energy substitution policies intended to alleviate the country's dependence on coal. Finally, while the industry of waste processing is now making a substantial contribution to China's 'green growth', it is the country's poorest, and those across its borders, who bear the burden of the industry's pollution.

How should we interpret the current crisis? How are Chinese citizens meant to organise themselves so that they might preserve and restore the environment they rely on and commonly share? This issue of Made in China deals with the rupture between unilaterally advocated projects for national and environmental renewal, and those 
popular voices, practices, and ideas which are usually left unregistered at the margins of the environmental debate. We look into the contemporary shapes and dynamics of Chinese citizens' engagements with the rejuvenation of their environment, and interrogate their potential for articulating workable alternatives. We give a name to our collective ethnographic intrusions into this topic: the 'commons'. While this is a word that has recently received a lot of attentionespecially thanks to the work of Elinor Ostrom-here we wish to extend its meaning. Ostrom has been rightly awarded a Nobel Prize for empirically demonstrating that ordinary people have the capacity to sustainably manage the environment without state supervision or the creation of market forces. They do so by managing the environment in common, that is by equipping themselves with collegially crafted rules that enable them to modulate their competing needs with a view to fostering their community's longterm flourishing and accommodating the fluctuating availability of natural resources.

We build on Ostrom's formulation, but we are wary of the ways in which her work has recently been co-opted by several international institutions and government agencies dancing to the tune of neoliberal politics. Since Garrett Hardin's Tragedy of the Commons, the concept of the commons has, in fact, served as a Trojan horse to smuggle a host of technocratic instruments into environmental politics. Instruments contrary to what the notion of the commons was originally meant to achieve: wealth concentration. Institutionalising the idea of the commons has meant the rekindling of top-down political proposals to achieve environmental sustainability that is also growth compatible through moreand allegedly better designed-market mechanisms and incentives. With this issue we wish to reclaim the term, the commons, in order to serve a different agenda.

To achieve this, we expand Ostrom definitions of rules and the environment. With 'environment' we don't simply refer to a collection of disposable matter, but to the assemblage of infrastructure, institutions, and life forms-the mutual relationships of which we humans have progressively reimagined and folded back into nature to pursue the best interest of our species. Stretching the meaning of the word 'environment' this way allows us to scrap the untenable nature/culture dichotomy underpinning Ostrom's approach, thus precluding the idea that sustainability can be achieved without the corresponding changes in our capitalist order. The idea of rules is subjected to a similar process of re-theorisation. Rules, and the codification of behaviour they entail, are only rarely the way Ostrom sees them: the product of an effort 'to achieve order and predictability' in a community of resource users. Rather, our case studies will show how processes of rule creation lead to alternative methods of action that may actually subvert the established order of resource extraction and consumption, fighting against the predictability of incessant capitalist expansion and commoditisation of nature.

What do we gain from looking for this expanded commons in China? What types of aspirations, creativity, and commitments do the commons give rise to in this country? Our ethnographic explorations of the Chinese commons will look into existing projects that seek to make the environment a common resource. We investigate the latent potential of everyday forms of resistance, refusal, and dissent for redrawing the frontiers of resource commodification in the increasingly degrading ecology of contemporary China. 


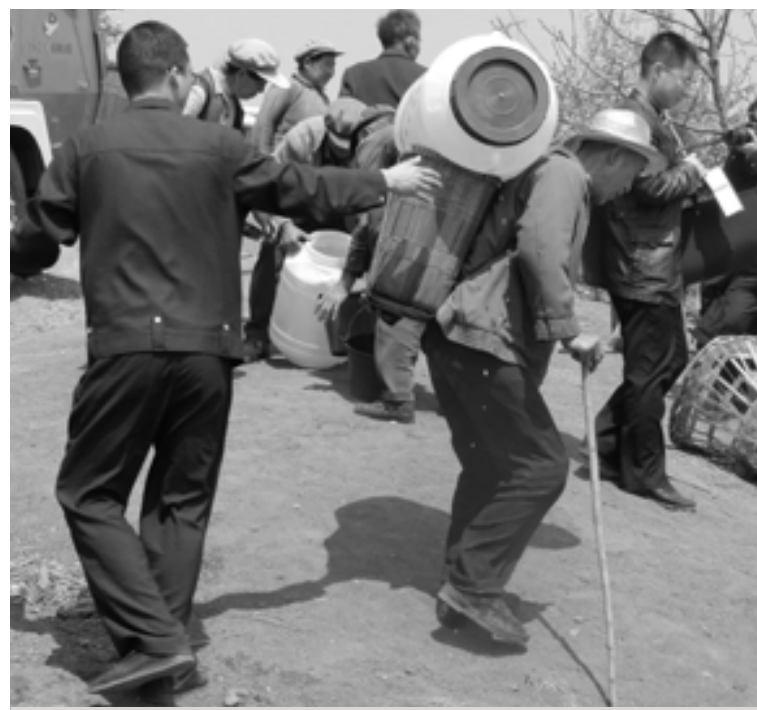

A water delivery initiative in northwest Yunnan. Famers receive barrels of drinking water from the government while fresh water from local springs is impounded and diverted elsewhere. Photo: Andrea E. Pia

\section{A Water Commons in China?}

\section{Andrea E. Pia}

The debate over China's environmental issues has given scant consideration to already existing popular alternatives to the topdown, growth-compatible governance of the country's natural resources. Forty years of Party-sanctified insistence on pursuing relentless economic development has seemingly suppressed alternative discourses in natural resource management. However, if we take closer look, we will find that at the grassroots there is no lack of alternatives. For instance, in contemporary rural China there are places where water is being managed as a commons.
As a one-time campaigner for the 2011 Italian Referendum against the privatisation of the country's domestic water services, I was excited to discover during fieldwork in Yunnan province that when briefed and asked about their views on the referendum proposals, most of my informants in the water sector were in fact sympathetic to them. They similarly hoped to protect water from marketisation and demanded the democratisation of its management.

As I write this essay, an ethnographic scene comes to mind. One day in 2012, I took part in negotiations between a Village Committee and a public-private enterprise regarding a water conservancy project that would have required the relocation of several of the village's households. The Committee pointed out that the proposed project mainly benefited the enterprise, which would gain access to state subsidies regardless of the efficacy of their infrastructure. The enterprise was legally required to win the Committee's assent to the project. To do so, they eventually had to accede to the local Party Secretary's request that the enterprise build a number of free-of-charge water dispensers for the newly relocated households at its own expense. Cases of political strong-arming for the sake of public access to water such as this had also been typical of Italian campaigners in the runup to the referendum. But such similarities begs the question: if Chinese people involved in everyday water politics were thinking along similar lines to Italian water activists, what was pre-empting the emergence of a similar movement in China? Obviously, the two countries are characterised by divergent political traditions and conceptions of social and environmental justice-for instance, a referendum is a not an option in China. However, in this essay I will explore whether the answer may have something to do with the thus far poorly theorised question of the Commons in China.

In what follows I will argue that in contemporary rural China there are places 
where water is already being managed as a commons. Making fresh water a commonly held resource entails breaking with global practices of water management in three ways. First, water has to lose its status as a commodity and be re-defined as a flowing component of the environment. When water is reconceptualised as a commons, the continuous local availability of its nurturing flow gains prominence over the marketmediated relationship between its supply and demand. Here, the notion of a nurturing flow illuminates the broadly defined lifesupporting functions exerted by water within both human and non-human ecosystems. Second, from the point of view of its management, water services cease to be run for profit, return on capital invested in water infrastructure lowers to zero, and ownership is reframed as a shared obligation to universal and sustainable provision. Finally, water services are opened up to public and associative participation into the crafting, enforcement, and monitoring of relevant rules with a view to preserving the life-nurturing qualities of the water flow over generations, as well as for non-human ecosystems.

\section{The Appeal of Techno- Political Frameworks}

So far the debate about China's current environmental issues has given little consideration to already existing popular alternatives to the top-down, growthcompatible governance of the country's endangered natural resources. Forty years of Party-sanctified insistence on pursuing relentless economic development has seemingly muffled the few dissenting voices and suppressed alternative discourses in natural resource management-such as those concerned with stewardship, care, maintenance, or even rejuvenation of the Chinese environment.

Instead, the language of techno-politics is holding sway. This is a mix of legal tweaks and engineering innovations-for instance, those behind the introduction of tradable water permits and huge water diversion schemeswhich, by preaching the appealing fantasy of the harmonious coexistence of China's present capitalist mode of development with nature, have slowly won over many of China's most belligerent environmentalists. Surprisingly, the case for the coexistence of continuous growth and sustainability has arguably found a favourable, if unlikely, currency for its propagation in the political doctrine of 'Ecological Civilisation' (shengtai wenming). While proposing a re-orientation of China's current model of growth (hailed by a felicitous start and some early success stories), in the sanitised version currently peddled by the Chinese government, Ecological Civilisation actually seems to be working to reinforce a chauvinistic and system-preserving distrust in local people's ability to redress the imbalance between efficiency in resource use and equity in allocation. What gets de-emphasised in the institutionalisation of Ecological Civilisation is the potential offered by empowering communities to democratically take environmentally sensitive decisions for themselves. Redressing this imbalance appears to me as a valuable short-term goal if at least to avoid some of the most obnoxious unintended consequences of techno-politics.

\section{A Problem of 'Distribution of the Sensible'}

The dominance of the top-heavy technopolitics of sustainability in China renders local people incapable of articulating and implementing alternatives. That does not mean to say that local people have no interest in developing alternative ways of dealing with environmental crises. Indeed, a good deal of empirical work has recently suggested that concrete local alternatives to businessas-usual are, if anything, in very high- 
demand, especially for those at the periphery of contemporary Chinese society. Citizens at the losing end of economic developmentincluding rural resettlers, ethnic minorities, and others-are all aware that environmental degradation is impacting them first. For instance, those who have to figure out how to fetch their clean water everyday usually seek out workable alternatives more pressingly than environmentally-blind urbanites. The analytical problem is, therefore, one of recognising the political agency of those who are elaborating viable counter-practices.

While the people directly engaged with the governance of natural resources may themselves ignore the extent to which the alternatives they put to work can be identified as sustainable or even counterparadigmatic within China's institutional architecture, the problem at stake here is one of visibility-or as Rancière would put it, one of the 'distribution of the sensible'. Rancière suggests that political fault lines are perceivable only to the groups who are sitting by them-in our case disenfranchised farmers living in water dispossessed communitieswhile their capacity to effectively overcome common predicaments in any political consequential way is publicly denied to them by their very proximity to such fault lines. Thus, counter-practices and counterenunciation are rendered unintelligible to anyone, their supporters included.

Public recognition does not just make alternative political practices widely known, but also efficacious. Up until now, the multifarious sustainability proposals championed by the Chinese government have taken the lion's share of the public debate on sustainability in the country, so much so that the very people who are concretely engaging with political practices of responsible, equitable, and un-marketed stewardship of common resources in contemporary China are not able to call them for what they are. Even worse, they struggle to see them as being in discontinuity from the demonstrably short-term solutions ushered in by those who consider the environmental question a technical problem requiring nothing more than the tools available within the imaginative horizon of capitalism.

\section{Canal Managers of Erstwhile}

Between 2011 and 2013, I spent eighteen months working with water bureaucrats and farmers as they went about implementing changes in the provision of irrigation and drinking water in their county. During this time, the price of drinking water doubled and the two local water agencies in charge of tax collection, infrastructure upkeep, and water development were transferred to hard budget accounts. Meanwhile, state and private funds were being diverted towards nearby cities. Farmers were also asked to reinvent themselves as members of Water Users' Associations (WUAs), alien organisations handed down to villagers by Mandarin-speaking universitytrained officials aimed at making the service more responsive to local needs and, most importantly, cheaper. Farmers were suddenly told to become familiar with the new norms that regulated the use, control, and exchange rights over water. They were warned that the government would hold them responsible for mismanaging the service they were now instructed to provide. During inaugural WUA meetings, the language of techno-politics was extensively used. While most of what was said would make direct reference to the science of the Commons, the farmers understood that they would now have to work for free as canal managers (guanzhang).

Prior to the advent of WUAs, being a canal manager had, in fact, been something everyone in this part of Yunnan was quite familiar with. It was a democratic and collectively financed position to which farmers were appointed on a rotating basis, according to a broader system of rules on local water management. Farmers appointed canal managers on every single 
portion of a canal adjoining a field or a house. They entrusted neighbouring members of this infrastructural community with reporting any misdelivery of water nearby. If managers were found guilty of mismanagement, a democratically appointed middlemanbacked by the local Village Committeewould identify a different manager for that portion of the canal until the next incident. A similar system of distributed responsibility and participation in monitoring existed for a network of privately-built, but collectivelyused, water wells widely accessible throughout the community. In essence, people from this area of Yunnan were managing the local water supply as a common resource and were doing it effectively. This system was run as a service to the community and not for profit. Rules to punish overdrawing had also been in force at some point, but were later abandoned as state officials took charge over environmental issues.

\section{The Activation of Ineluctability}

What is most surprising is not that local people were aware and had extensive experience of cooperating on water management well before anyone from the outside had instructed them on the matter. Rather, the surprising bit of this story is that local farmers were willing to accept the cooptation of their distributed and equitable mechanism of organised water delivery. This, at the hands of a system that promised nothing except increased levels of corruption, higher overall running costs, and dwindling state support.

Indeed, the language of techno-politics is successful because it activates a particular explanatory framework that resonates among the people-that of the moral superiority of scientific management. Farmers would assert that countryside life was bound to disappear in China and that rural dwellers had to adjust to a different lifestyle or migrate elsewhere.
In their opinion, the previous system was backward and not keeping pace with more scientific forms of management represented by the WUAs. While a few younger informants held the view that locals should collectively resist the government or businesses whenever water was taken away or polluted, in general the water sector reformers had been quite successful in framing the problem of sustainability exclusively as one of science and supervision. The idea of governing water 'the old way' (laoguiju) was thereby made redundant-a survival component of an important, but now technically disposable, condition of pre-scientific Chinese water management. As mentioned above, one key idea of the notion of the Commons is that of inclusive participation in the decisionmaking process concerning the management of natural resources. As this power seemingly fades away from north-east Yunnanese communities, so is the sense of meaningfully being part of one's community and the capacity to care for it. The Rancierian gesture I resorted to here was to acknowledge the unrecognised capacity of local Chinese people to challenge the tacit ordering and distribution of the things we have in common in counter-paradigmatic ways. As one Italian water referendum campaigner used to say during activists' assemblies: 'They want to convince us we don't care about how water gets delivered.' My ethnography shows that it is about time we start to re-convince ourselves of the contrary.

\section{Andrea E. Pia}

Andrea E. Pia is a Fellow in the Anthropology of China at the London School of Economics and Political Science. His research examines Yunannese street-level officials and rural residents as they push the boundaries of cooperation and antagonism over the task of maintaining access to water in the Chinese periphery. 


\section{Amateurism and Our Common Concern for Biodiversity}

\section{Timothy McLellan}

Treating the environment as a common resource often implies not only local, but also supralocal, even global, collectives of concerned stakeholders. While engaging with local actors, these stakeholders frequently insist on the need for a 'professional' approach. Examining an international project aimed at introducing biologically diverse agroforestry in a county in southwest China, this essay describes a more 'amateur' approach adopted by one international organisation. It argues that this amateurism demonstrates that, even within global professional organisations, there is an appetite for a new, more spontaneous, approach that values local knowledge and practices.

This article is based upon work supported by the National Science Foundation under Grant No. 1357194, The Cornell East Asia Program, and Cornell's Mario Einaudi Center for International Studies. To ensure the anonymity of my research subjects, I use pseudonyms for all institutional, personal and place names.
Treating the environment as a common resource often implies not only local, but also supra-local, even global collectives of concerned stakeholders. The Convention on Biological Diversity, for example, asserts that 'the conservation of biological diversity is a common concern of humankind'. An agroforestry project in Qingshan township, Yunnan province, was one such effort to establish the environment and biodiversity as a common concern for a global community of actors.

A Western cosmetics company, Metelli, sponsored the project. Launched about a decade ago, the project's goal was to introduce ecologically complex, biologically diverse agroforestry to Qingshan. According to a Metelli corporate social responsibility officer, since the company's products depend on nature for their ingredients, Metelli has a responsibility to give back to the environment. Here, Metelli sees itself as a responsible stakeholder alongside local communities, and attempts to insert itself as a collaborator in the management of Qingshan's environmental commons.

This article is based on two years' participant observation at the Institute for Farms and Forests (IFF), an international agricultural research organisation who participated

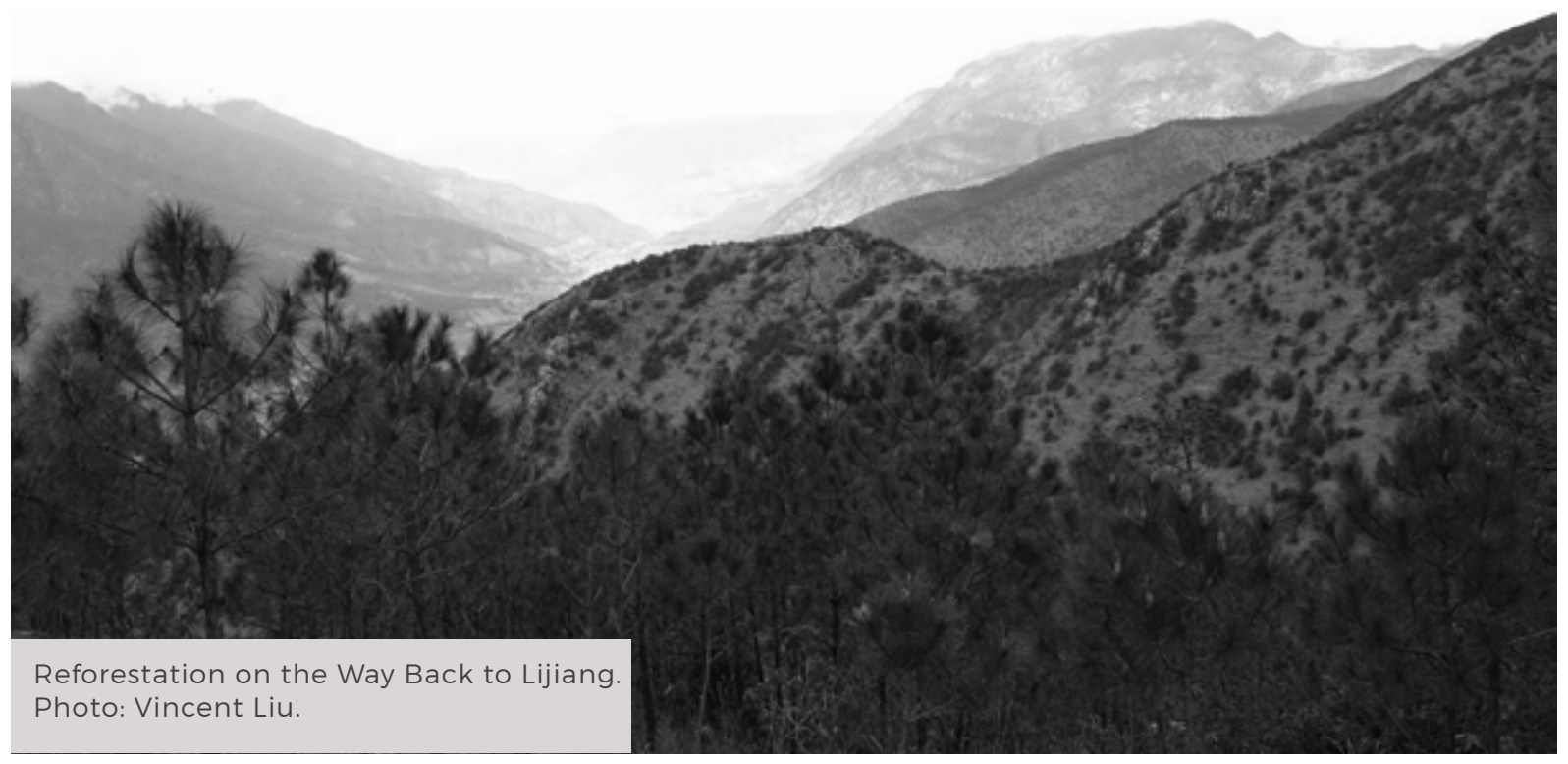


in the project. Inspired by critiques of academic professionalisation, and associated explorations of the virtues of amateurism, I describe the amateur engagement that IFF attempted to bring to this project. I argue that this amateurism demonstrates that, even within global professional organisations like IFF, there is an appetite for what Anna Tsing calls 'creat[ing] scenes that exceed or escape professionalization.’

\section{Pursuing Amateurism}

To implement Metelli's vision for Qingshan, several organisations were recruited. First, a Western NGO with experience in agroforestry, Arboreus, and a local NGO called Shehui. Several years into the project, Metelli and Arboreus had become concerned by Shehui's lack of agri-environmental expertise. IFF was therefore recruited to the project, bringing with it its experience in agroforestry and soil management. In contrast to the other project partners, IFF's involvement was rather informal. IFF had a lucrative contract with Metelli to facilitate laboratory research on local medicinal plants with the potential for use in cosmetics. As such, when they offered assistance to Metelli's Qingshan project, IFF asked only for funds to cover travel expenses. The resulting absence of the kind of formal deliverables that ordinarily tie IFF's funding promised IFF scientists an unusual degree of latitude.

Having provisionally devised soil management practices for Qingshan, and established participatory principles according to which these ideas should be communicated, the IFF team (of which I was a member) ran several workshops in Qingshan. While IFF's enthusiasm for 'participation' embraced a central tenant of contemporary development professionalism, IFF's designs for the project were out of sync with certain contemporary trends. First, Qingshan workshops were each designed from scratch and as unique events.
Workshops did not adhere to a previously established protocol, nor did IFF staff imagine their workshops to be replicable on a wider scale. This contrasted with certain other projects where IFF employed protocols or 'toolkits' that had been designed to be transferable across time and space.

Second, IFF scientists envisioned the process of learning from Qingshan farmers and getting to know the landscape over which they sought to establish a common concern as a slow and gradual process. Workshops were organised sporadically, and in response to the project as it unfolded. Each visit was approached as a further opportunity to learn. This contrasts with certain iterations of participatory rural appraisal (PRA) delivered as rapid, one-off workshops. In such versions of PRA, Terry Rambo suggests, development professionals 'claim to understand everything by sponsoring a three-to-four-day rapid appraisal exercise'. Here, participation is co-opted by the very forms of professional 'arrogance' Robert Chambers intended for it to address.

In the Qingshan case, far from the 'understanding [of] everything' promised by certain PRA toolkits, IFF scientists' ad hoc workshops created a degree of anxiety. Whereas transferable toolkits often imply a certainty in what should be done, the IFF team were at each stage anxious as to whether their ad hoc activities would perform as hoped: Had we really generated a space for dialogue, or were farmers simply telling us what we wanted to hear? Would the proposed soil management strategies really benefit Qingshan? In this respect, whereas scientists are often accused of adopting 'technologies of hubris', the anxieties generated by IFF's ad hoc approach suggest the seeds of what Sheila Jasanoff calls 'technologies of humility'.

If contemporary research and development professionalism is characterised by replicability, scalability, transferability, rapidness, and self-confidence; I am going to describe the ad hoc, single-site, one-off, slow, 
anxiety-inducing, and often deeply personal engagement that IFF pursued as a form of amateurism.

\section{The Project Falls Apart}

A soil management plan developed at an early workshop was for winter cover crops to be planted in-between the rows of notyet-harvested primary crops. Susanna, an IFF soil scientist, had proposed this early planting strategy as a solution to the farmers' experience that cover crops did not survive Qingshan's dry winters. When it came to the appropriate time to sow cover crops, however, we discovered via Shehui's local project manager, Xuejian, that the farmers had decided to delay planting until after harvest. According to Xuejian, since the rains in Qingshan had begun very late that year, farmers expected that rains would also finish later than usual. As such, the farmers reasoned, they could afford to postpone cover crop planting until after harvest.

When this message was relayed to Susanna she was dismayed. She feared that the rains might not continue late, and having persuaded Qingshan farmers to give cover crops another try, she did not want them to fail. Susanna and her colleagues, moreover, were frustrated that Shehui had taken several weeks to inform IFF of the farmers' new approach. In this respect, IFF's attempt to situate itself within a larger collective was challenged by the fact of its exclusion from a significant decisionmaking process. In a sense, this exclusion denied IFF's implicit claim on Qingshan's biodiversity as an object of common concern.

IFF's response was to organise a further workshop in Qingshan. The difficulties in making this workshop happen, however, came from beyond Qingshan. IFF had initially arranged a workshop directly with a community leader in Qingshan, but Xuejian contacted IFF to cancel the workshop. Shortly thereafter, we received a communication from Arboreus explaining that all IFF activities in Qingshan must be pre-approved by both Shehui and Arboreus. The workshop did eventually go ahead, but following the workshop, wrangling continued amongst Shehui, Arboreus, and IFF. Whereas IFF scientists had anticipated and embraced the practical and ethical challenges of establishing relations with Qingshan farmers, the unexpected labour of maintaining relationships with extra-local partners emerged as an impossible headache.

Some IFF colleagues attributed the project's failure to the incompetence of their project partners. In one instance, Xuejian explained to IFF scientists that Arboreus's training in Qingshan had attempted to impress upon farmers the importance of three metre spacing between trees-a guideline, Xuejian told us, that took no account of tree species or location. For IFF scientists, this absurdly global approach to tree propagation confirmed Arboreus's ignorance. The failure of the collaboration, however, can also be attributed to an incongruity between the approaches of IFF and its project partners. As well as their incompetence, Arboreus's tree-spacing guidance showed their professionalism: it reflected their understanding of environmental sustainability as a global, scalable process.

Embracing development professionalism, Arboreus were constantly contemplating how their activities might be replicated across ever-larger scales. Indeed, this was part of the reason they wanted not only prior notification of IFF's activities, but also written reports after each visit to Qingshan. On one occasion, impressed by a soil management booklet Susanna had produced specifically for Qingshan farmers, Arboreus asked whether IFF might create a similar set of booklets for them to use globally.

IFF, by contrast, approached the project much more narrowly: as a project in Qingshan. We were seldom distracted by the question of how to replicate or upscale activities in Qingshan. This is not to say that IFF is not 
ordinarily subjected to such imperatives. At a recent regional planning meeting, for example, an IFF communications officer described how the organisation must learn from marketing professionals and build a global brand for itself. Many IFF staff members were uncomfortable with such demands. Indeed, part of the Qingshan project's appeal to IFF staff was perhaps that it presented an opportunity to work outside of this global scale and the accompanying imperatives of professional research for development. In this sense, the Qingshan project promised the chance to play the amateur.

By drawing attention to IFF's amateurism I do not mean to imply that, unimpeded by their supra-local partners, IFF would inevitably have made the project a resounding success, or that amateurism escapes the contradictions and tensions inherent in efforts to make biodiversity a common concern in a world that is fundamentally unequal. Nevertheless, like China Scherz's account of a Catholic charity's refusal to adopt the logic of development donors, IFF's all too brief flirtation with what I have called amateurism shows that, even within a prominent international organisation like IFF, there are seeds of activities that 'exceed or escape professionalization'.

\section{A Victory for Professionalism}

In this Qingshan case, however, Arboreus's professionalism won through. Shortly after the shambles of IFF's negotiations to run a workshop, Arboreus commissioned an audit of the project. One outcome of the audit was for Metelli to belatedly act upon an IFF suggestion to establish experimental agroforestry plots in Qingshan. IFF responded with a detailed proposal for the plots, but some at IFF half hoped Metelli would decline to fund the proposal, and thereby give IFF an excuse to leave the project. The headache of collaboration with supra-local partners had led to a loss of faith in the project ever running smoothly. Moreover, the professional imperatives to formalise project plans and project goals, as well as to undergo audits and manage budgets, robbed the project of the amateur quality that had initially sparked IFF staff's now fading commitment to, and hope in, the project.

Transferring on a flight back to the United Kingdom after completing fieldwork, I spotted photos of farmers planting trees in Qingshan displayed at a Metelli airport concession. As an example of Metelli's corporate social responsibility, the display invited consumers to share in Metelli's concern for global biodiversity. In effect, the invitation to purchase Metelli cosmetics was also an invitation to join the collective the company had established with Qingshan farmers, and to thereby participate in the sustainable management of environmental commons. Of course, from the point of view of IFF scientists, this collective and its management of Qingshan's biodiversity had been no great success. Metelli's marketing strategy, however, may serve as a reminder that just as challenging as it can be to establish meaningful collaborations around environmental commons, constructing the façade of a global collective can be rather easy. Indeed, in an era where organisations like IFF are turning to marketing in their efforts to professionalise, we should perhaps wonder if environmental commons would be better off in the hands of amateurs.

\section{Timothy McLellan}

Timothy McLellan is a PhD candidate in anthropology at Cornell University. He has a BA in Law and Chinese from The School of Oriental and African Studies, and an MSc in Law and Anthropology from The London School of Economics. 


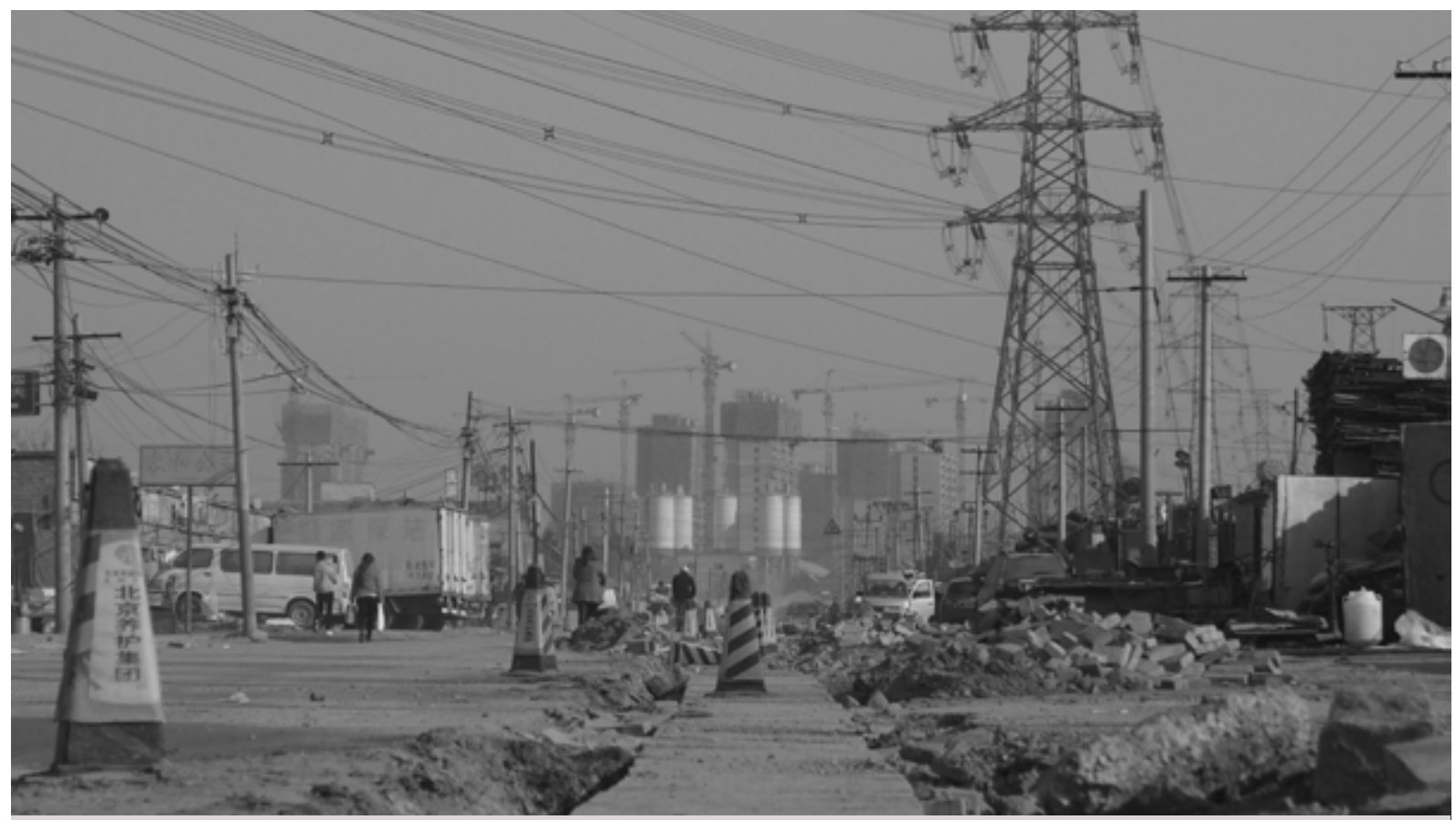

Urbanisation on the outskirts of Beijing. Dongxiaokou, late 2014. Photo: Carlo Inverardi-Ferri

\section{Commons and the Right to the City in Contemporary China}

\section{Carlo Inverardi-Ferri}

This essay outlines the development of Dongxiaokou, an urban village on the outskirts of Beijing. Until urban redevelopment projects accelerated its demolition in recent years, this informal settlement was home to a massive population of migrant workers, who had made this place their base for entering the capital's labour market. The story of Dongxiaokou provides interesting insights into the process of commodification of land in contemporary China. In particular, it highlights the tension between land used as a common resource by migrants, and land utilised as a way to produce economic profits for real estate development.
This short essay tells the story of Dongxiaokou, an urban village in the northern outskirt of Beijing, infamously known in the press as the 'waste village' (feipincun). Until urban redevelopment projects accelerated its demolition in recent years, this informal settlement had been one of the biggest in the metropolis. Situated between the Fifth and Sixth ring road, around ten kilometres from the city centre, it hosted a massive population of migrant workers, who had made this place their home and used it as a base to enter the Chinese capital's labour market.

The story of Dongxiaokou provides interesting insights into the process of commodification of land in contemporary China. The article engages with this issue and highlights, in particular, the tension between land used as a common resource by migrant workers and land utilised as a way to produce economic profits for real estate development. There are at least two good reasons why this story is worth telling-one related to the status of land use rights in China; the other to the nexus between labour and migration in the country. This account of Dongxiaokou 
reasserts the centrality of an old question: in a geography where capitalism brings about a growing commodification of space, who owns the right to the city? In other words, if we consider the urban space as a common resource, who has the right to use it and under what conditions?

\section{Land Rights and Migrant Labour}

Surprisingly enough, while in the last decades China has undergone a number of subsequent shifts towards economic liberalism, land somehow remains a conundrum for the country's 'socialist market economy'. While land has certainly been subjected to the effect of the marketisation of the economy, it has also remained strictly tied to the Party-state. Today there are two main types of land property rights in China. While urban land is formally owned by the state, rural residents exercise collective ownership in the countryside. In theory, rigid regulations control the use of this resource; in practice, however, ambiguity in the legislation has resulted in an empowered Party-state, which has ended up holding sway on land-related decisions in both cities and countryside.

A common practice in many rural villages involves the development of collectivelyowned land into urban and commercial functions as a way for local administrations to create new streams of revenue. While some localities have been more successful than others, this phenomenon has appeared almost everywhere in the country. In particular, these practices have multiplied in border areas between the city and the countryside, where many rural villages have been completely transformed in their geographies. This rural-urban friction has also led to another phenomenon driven by the increasing marketisation of the economy and the process of commodification of land. The sprawling of metropolises into suburban areas has resulted in the recurrent inclusion of rural villages into urban districts. Rural land is thus subjected to a two-fold process of commodification. First, it is informally developed into urban and commercial functions as a means to make a profit for rural areas. Second, these hybrid spaces are again subsumed by urban redevelopments.

The story of Dongxiaokou, a small rural village that in a few years became one of the largest informal settlements in the Chinese capital, is particularly revealing of both dynamics. In the early 2000s, the village rented most of its land to migrant workers coming from outside the municipality of Beijing. Its proximity to the city centre made it a convenient place to settle down and find work opportunities in the metropolis. When the first migrants arrived, local cadres welcomed them and accommodated the newcomers in uncultivated fields, which were rented out as a way to drive new revenues into the village.

Wealthy migrants rented big plots of land that they then divided and sublet to less well-off migrants, who in turn established their dwellings and economic activities in Dongxiaokou. Very quickly the village population grew from little less than two thousand people into an agglomeration, according to some sources, of almost thirty thousand inhabitants. Interestingly, Dongxiaokou quickly became a local hub for waste recycling activities growing in scale and scope. As one of my informants claimed in a personal communication, in few years Dongxiaokou was transformed into 'one of the biggest scrap distribution centres (feipin jisandi) in the entire country.'

A complex network of buyers and suppliers for all sort of waste materials developed in the village. During the day, local recyclers roamed the wealthy neighbourhoods of Beijing in search of valuable products, such as used mobile phones or old compressors. In the evenings, they came back to Dongxiaokou to resell their products to middlemen who, in 
turn, resold them to manufacturing companies in nearby regions. A large number of complementary businesses, such as mechanic workshops, logistics firms, groceries, and restaurants, also quickly flourished in the village.

Hundreds of family-owned enterprises dominated the landscape. They all looked more or less the same. Behind a metallic gate was a rectangular courtyard where old newspapers, waste wood, plastic bottles, used electronics, or anything else with a commercial value was stored. In one of the corners of the yard there was always a small building, usually composed of two rooms, where an entire family lived. Sometimes a dog was chained to one of the walls to guard the yard.

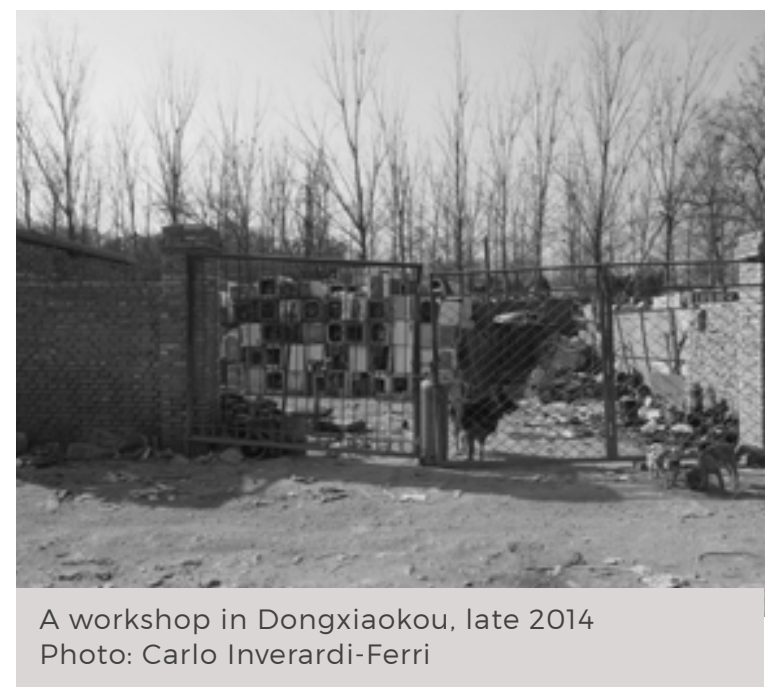

\section{A New Generation of Petty Capitalists}

Interestingly, while academia and the media have paid much attention to different generations of migrant workers in their role as wage-labourers, the rise of Dongxiaokou paints a less familiar picture. It tells the story of small family-owned firms and self-employed entrepreneurs, or in other words, petty capitalists. It is a story of what some define as the informal economy: a heterogeneous sector that crosses many different industries, and employs a large proportion of the population in contemporary China. It is not my goal to romanticise this phenomenon, which raises serious questions of occupational health and safety, as well as issues of local citizenship and environmental justice, but rather to underline what I believe to be one of its most peculiar characteristics. Migrants in Dongxiaokou-at least a good portion of them-enjoyed a relatively high level of freedom and mutual support, being part of a local society that conceived of their resources-labour and land-as means of common subsistence.

Dongxiaokou was not an isolated case. A report by the United Nations published in 2013 estimated that the informal recycling sector in China comprised twenty million people, and that it was organised in a myriad of informal settlements scattered all over the country. While numbers certainly cannot give an accurate account of the great variety of businesses that this industry creates, they are nevertheless useful to provide a general idea of the magnitude and impact that these activities had, and continue to have, on Chinese metropolises. This involves the creation of employment opportunities on the one side, and the production of physical landscapes on the other side.

Dongxiaokou was not a new phenomenon either. In their work on the 'Henan village', Béja and colleagues documented the emergence of these urban and economic spaces as far back as the 1990s. The authors analysed a settlement not too far from Peking University-now long demolished-in many ways similar to Dongxiaokou. They did so through the notion of desakota (desa meaning 'village' and kota 'urban' in Bahasa), a concept that was first employed in studies on the urbanisation of Southeast Asian countries. In Indonesia, the metropolitan sprawl had produced a peculiar combination of rural and non-rural activities, where areas dedicated to the production of rice were mixed with the 
urban landscape. Drawing a parallel with the Indonesian context, the authors described the Henan village as a peculiar Chinese desakota.

The fate of Dongxiaokou was decided in the 2000s. This space on the urban periphery, which had been transformed through the agency of a group of migrant workers, and which provided a fundamental service to the city-waste recycling-did not resonate with the conceptions of modernity that official planners held for Beijing. When urbanisation reached the borders of Dongxiaokou, space had to be made for the new real estate projects. As a result, demolitions of the 'waste village' of Dongxiaokou accelerated in 2015. The place that previously buzzed with economic activity was again geographically transformed. Workshops that were filled with all sort of valuable products became empty fields, as their occupants had to relocate to other parts of the city. Roads were silent, except for the sounds coming from the new infrastructural works planned by the municipality. Having lost their usual clientele, shops closed down, and most dwellings were levelled.

\section{A Social Community}

As the story of Dongxiaokou suggests, two different levels of urbanisation exist in contemporary China. The first is a process mediated by the state that operates inside the administrative boundaries of the city; the second is an unofficial one, which goes beyond these boundaries and occurs at the margins of the metropolis or in the countryside. Here, migrant workers, attracted by the possibility of improving their material lives, enter Chinese metropolises and create particular urban economic landscapes, while suburban villages benefit economically from their presence. Yet, official planning recurrently subsumes these spaces.

These different modes of urbanisation also mirror contrasting ways of creating and living in the city. Enclaves of informality-and the specific use of land operated in urban villagesreflect the way less-privileged groups make a livelihood, rather than a strategy to produce profits from land development. While they come from poorer rural regions and moving into metropolises, friendship and kinship networks support the adventures of these migrants who lack any basic formal right to the city. As a dweller in Dongxiaokou clearly pointed out, the social community that inhabited Dongxiakou provided important support to migrants. In his words: 'Being here is like being back home... Like this, it is easier to do our business.'

As this quote suggests, urban villages are microcosms of people and relations that represents a social community and not only economic outcomes. Here the physical and social dimensions of land are strictly intertwined with the everyday livelihoods of the people that inhabit these spaces. Their redevelopment is thus a process that brings about a destruction of these communal spaces, highlighting once more the need to ask an old-but urgent-question: who has the right to the city in contemporary China?

\section{Carlo Inverardi-Ferri}

Carlo Inverardi-Ferri (DPhil Oxon) is a Post-Doctoral Fellow in the Department of Geography and Global Production Networks Centre at the National University of Singapore. His work is situated in the field of economic geography. The author thanks Jasnea Sarma, Andrea Pia, and the editors of MIC for their valuable comments on previous versions of this short essay. 


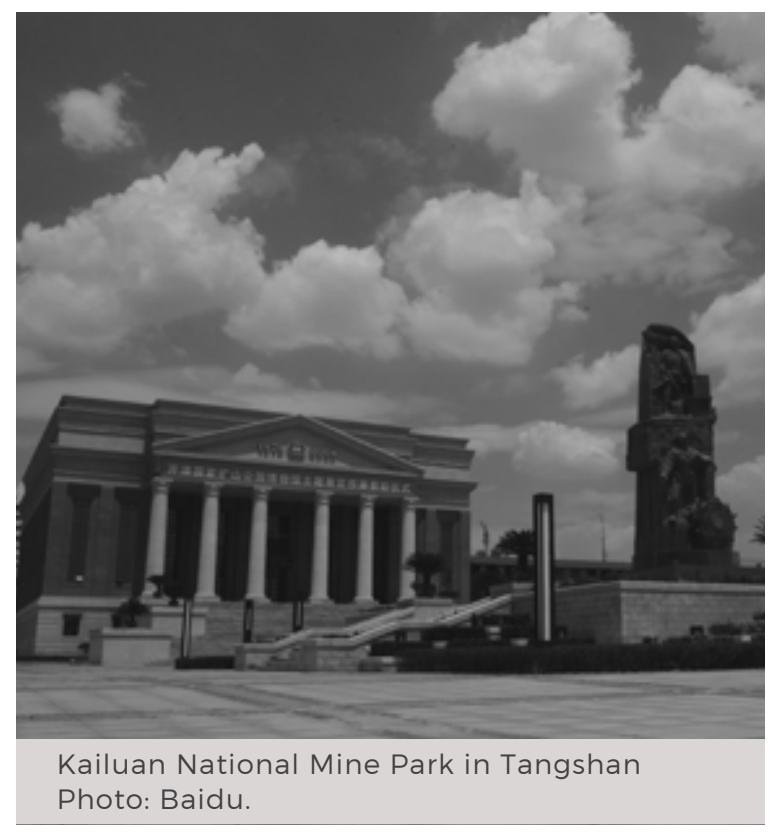

\section{Burning Coal in Tangshan: Energy Resources as Commons}

\section{Edwin Schmitt}

The extraction and use of energy resources to drive modernisation has been one of the key concerns of the Chinese Communist Party. By tracing the history of coal mining in China, this essay argues that the physical characteristics of coal as a common pool resource have shaped the ways in which coal has been harvested and used, as well as the political and institutional structures that have developed around its governance.
While it is not always well recognised, energy reserves are by far the most abundant and yet most conflict-ridden common resource. In this essay, I will look at the common pool of energy resources in China, specifically coal mining and coal-fired power plants. Perhaps the most famous description of the commons comes from Garrett Hardin's deceptively simple rendition: in order to prevent the ruin of common resources, society requires a set of rules for harvesting those resources so that they can be put to use. Originally the debate was about whether the most optimal rules could be found through a free market or a planned economy, the latter of which is the direction that China took. Elinor Ostrom provided a third insight into the debate, arguing that the form these rules could take was not that important as long as they were embedded into the everyday practices of a society.

Although he does not couch his argument in terms of the commons, Timothy Mitchell has recently argued that the physical characteristics of an energy resource has a strong relationship with the way these rules might develop and become socially embedded. According to Mitchell, democratic politics initially became entrenched in Europe during the Industrial Revolution as a result of the need for coal miners to collaborate together while deep underground to safely remove this energy resource from the earth. These strong collaborative relationships became essential when coal miners, as well as those responsible for transporting the coal from mine to factory, went on strike. The dense physical characteristics of coal allowed striking workers to ensure that the flow of energy, and therefore the flow of economic development, would grind to a standstill. This collaborative nature that emerged in the mines was a natural pairing with democratic politics when workers began to unionise and demand better conditions and pay from the capitalist owners of the mines. 


\section{The Early Democracy of Chinese Miners: Anyuan vs. Kaiping}

Mitchell's history of coal begs the question: why did similar democratic principles not emerge among coal miners in China? In some ways they did, at first. One of the most famous examples comes from the Anyuan Mines, Jiangxi province during the 1920s where the Chinese Communist Party (CCP) planted the seeds of the Communist Revolution. It was the collaborative nature of the miners that allowed the Party to develop Anyuan into a kind of 'worker's university' for disseminating strategies for unionising and calling worker strikes around China. Many of the principles practiced at Anyuan were rooted in democratic principles of equality while, of course, also being embedded within a Marxist-Leninist ideological call for class struggle. After attacks by the Kuomintang, the workers were forced to abandon the mine but ended up forming the First Red Army of China. As we will see, this militarisation of the workers had consequences for why China's coal miners eventually organised in a manner that does not fit Mitchell's narrative.

While the miners in Anyuan were initially democratic, workers at the Kaiping Mines in Tangshan, located in Hebei province, were suppressed by a capitalist and colonialist system of exploitation. Most of China's early industrial labour force was recruited from rural populations far from industrial centres. It was up to a group of labour contractors (batou) to bring workers and owners together, but this created an effective barrier that often prevented the British owners of the mine from ever hearing the needs of their workforce. A strict hierarchy at Kaiping ensured that the rules and decisions made for governing the mining of coal received little or no input from those labouring to remove the energy source from the earth.
In late 1948, Tangshan was 'liberated' from the rule of the Kuomintang by an elite unit of the People's Liberation Army (PLA). As a first order of business, two high-ranking officers, Li Chenglong and Yan Dakai, respectively took control of the Tangshan Electric Plant and the Kailuan Coal Mine (the new name for the Kaiping mines). At that stage, it was imperative for the PLA to quickly revive the productive forces that would ensure a stable supply of weaponry to the military. Tangshan was not only a centre of energy production, but it also produced military vehicles needed to keep the PLA mobile as the CCP cemented its power across China. Since there were no CCP members at the power plant, Li Chenglong spent the first two years focussed on indoctrinating the plant workers into a socialist mode of production. While workers were considered equal 'owners' of the plant, Li installed a new hierarchy for organising decision-making, by establishing worker's brigades that had to answer to their brigade leaders, who in turn had to answer to the plant leader. This institutional hierarchy, mimicked that found within the PLA.

Moreover, scientific and engineering brigades were established, so that educated elites were integrated into the decisionmaking process of the plant. Regarding energy production, the plant leader took the input of scientists and engineers quite seriously. While the plant leader oversaw day-to-day decisionmaking, the amount of energy produced and supplied to the electrical grid was a decision made by the Tangshan Electrical Bureau in consultation with the goals established by the Ministry of Water Conservancy and Electric Power of Hebei province and the Central Government. While this was certainly a new hierarchy, the fact that decisions on these matters were being made far away from the plant was nothing new to the workers. Similar processes were taking place at the Kailuan mine as well. 


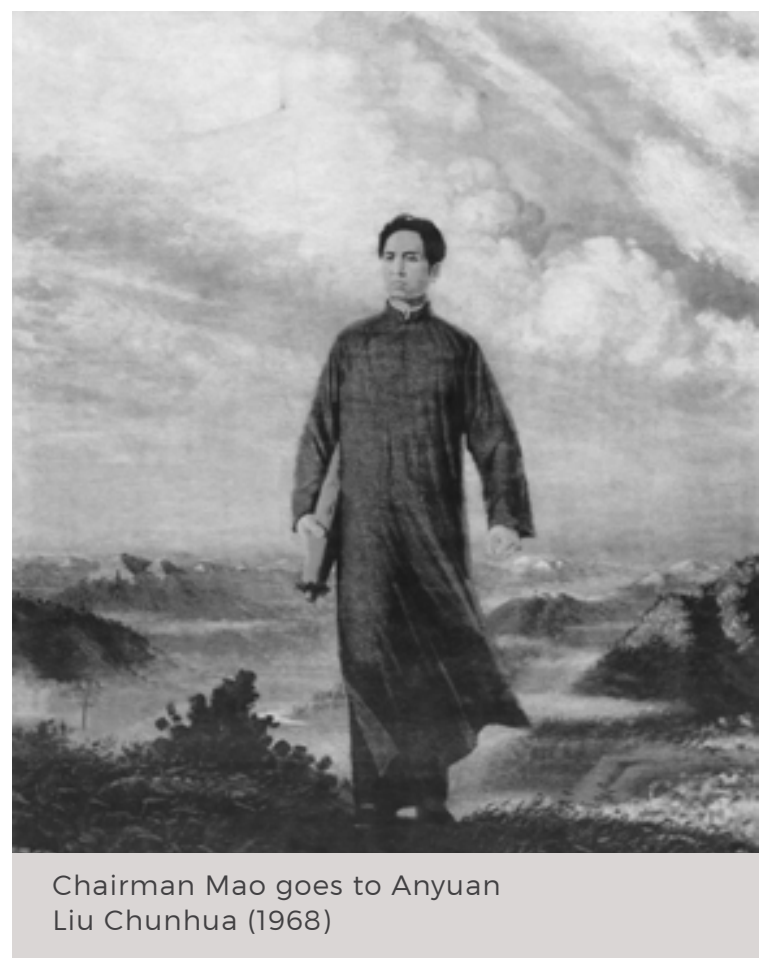

\section{The Rise of Chinese Unions}

One major difference with the hierarchy found in the older batou system was the establishment of the worker's unions. Although it was a country-wide union in name, the official All-China Federation of Trade Unions (ACFTU), was hardly a monolithic entity across China. At the grassroots level, both the Kailuan Coal Mines and Tangshan Electric Plant established unions that represented the workers of their respective facilities. These unions allowed the voice of the workers to be heard within the Party and could be considered an outgrowth of the ideas that developed during the Party's time at Anyuan. Throughout the first thirty years of the People's Republic of China (PRC), the unions created a certain level of antagonism that required the military hierarchy described above to cooperate with the workers through their union leaders. Moreover, the transmission of Party ideology was dependent on the unions and in some cases this would result in situations beyond the control of the plant leader. For instance, during the second Anti-Rightist Campaign of 1959, the workers forced Plant Leader Li Bin to resign and heavily criticised him for his supposed rightist positions regarding electricity production. It was not until 1962 that he was forgiven, eventually becoming the plant leader for the duration of the Cultural Revolution. However, there were also times throughout the Great Leap Forward (19581962) and Cultural Revolution (1966-1969) when ideological shifts provided the plant leader with exceptional power and forced the workers to commit to dangerous production quotas leading to multiple accidents.

In other words, while a new hierarchy was put into place that still provided a degree of separation between the workers and decisions for harvesting and utilising energy resources, there was always a struggle between a group of decision-making experts and the workers. Perhaps the potential for a more democratic power structure did exist in early PRC history. However, we should also keep in mind that the workers' unions were isolated within their work unit. The union at Kailuan Coal Mine was strictly focussed on providing a voice for the miners and had no control over where the coal mined from Kailuan would end up. The only real connection between the Kailuan Coal Mine and the Tangshan Electric Plant unions would be when the chairperson of the union or a few worker representatives might meet at the Hebei Provincial Worker's Union Annual Conference.

Multiple worker unions never collaborated, which is why the idea of a sector-wide strike preventing the flow of energy resources was unthinkable. In some ways, we might even argue that the ability of the state to ensure the flow of energy from the common pool of resources into the economy was at least as effective in this socialist military hierarchy as it ever was within the capitalist economies of Europe. Perhaps we could say that the institutionalisation of a military hierarchy for organising energy resource management that 
included the ability of the union to provide workers with a voice was somewhat similar to the nested institutions described by Ostrom.

\section{A Model for Energy Management}

Over the years, Tangshan's energy production was presented as an institutional model to the rest of the country, not unlike the more (in)famous Daqing Oil Fields. Books were distributed to coal-fired power plants around the country with titles like 'The Situation of Tangshan Electric Plant Cadres Participating in Labour'. Both the Tangshan Electric Plant and the Kailuan Coal Mine regularly graced the pages of the People's Daily, with the latter being praised for its success at implementing cutting-edge technology in removing coal from the earth. More recently, the messages have begun to shift after a plan to expand the plant was accused of violating environmental policies in 2007. Today, both the Kailuan Mine and the Tangshan Electric Plant have been shut down and turned into parks, similar to those discussed by Maris Gillette in this issue (see p. 25). Just a year ago, the People's Daily even published a detailed article about the successful remediation process taking place at Kailuan Coal Mine. Even in 'death', the mine and the power plant are being used as examples to follow as China enters the new historical phase of 'Ecological Civilisation' (shengtai wenming).

Naturally, the top-down nature of Ecological Civilisation that ensured the decision to close the plant and mine had little to do with what the workers themselves wanted. What is ironic about this story is that the top-down hierarchical political structure from which the Ecological Civilisation ideology emerged originated with the need to ensure that the Chinese military had access to highly polluting energy resources, such as coal. Regarding the commons, we can see that a top-down method can be used to prevent access to common energy resources just as it can organise the harvest of them. My focus here has not been on the effectiveness of this hierarchical structure to manage those resources over the long term-others have already argued that it did a very poor job. Instead, I have been trying to show how a certain kind of social structure and political decision-making emerged from the hierarchical rules for governing commonpool energy resources in China. While some aspects of democratic decision-making did find their way to China's coal fields, the bonds between coal miners that Mitchell described in the European context were prevented from developing into a true political force because of the institutional structure of the CCP. In other words, the material aspects of the environment are not ineffectual when it comes to the rules we devise for governing the commons, but nor do they solely determine the structure of those rules or the political power needed to enforce them.

\section{Edwin Schmitt}

Edwin Schmitt is a Postdoctoral Researcher at the University of Oslo. In the past, he has conducted ethnographic and survey-based research on environmental consciousness in the city of Chengdu. His current project aims to examine how the production of energy has been connected to the formation of, and changes within, the broader political power structures in recent Chinese history. 


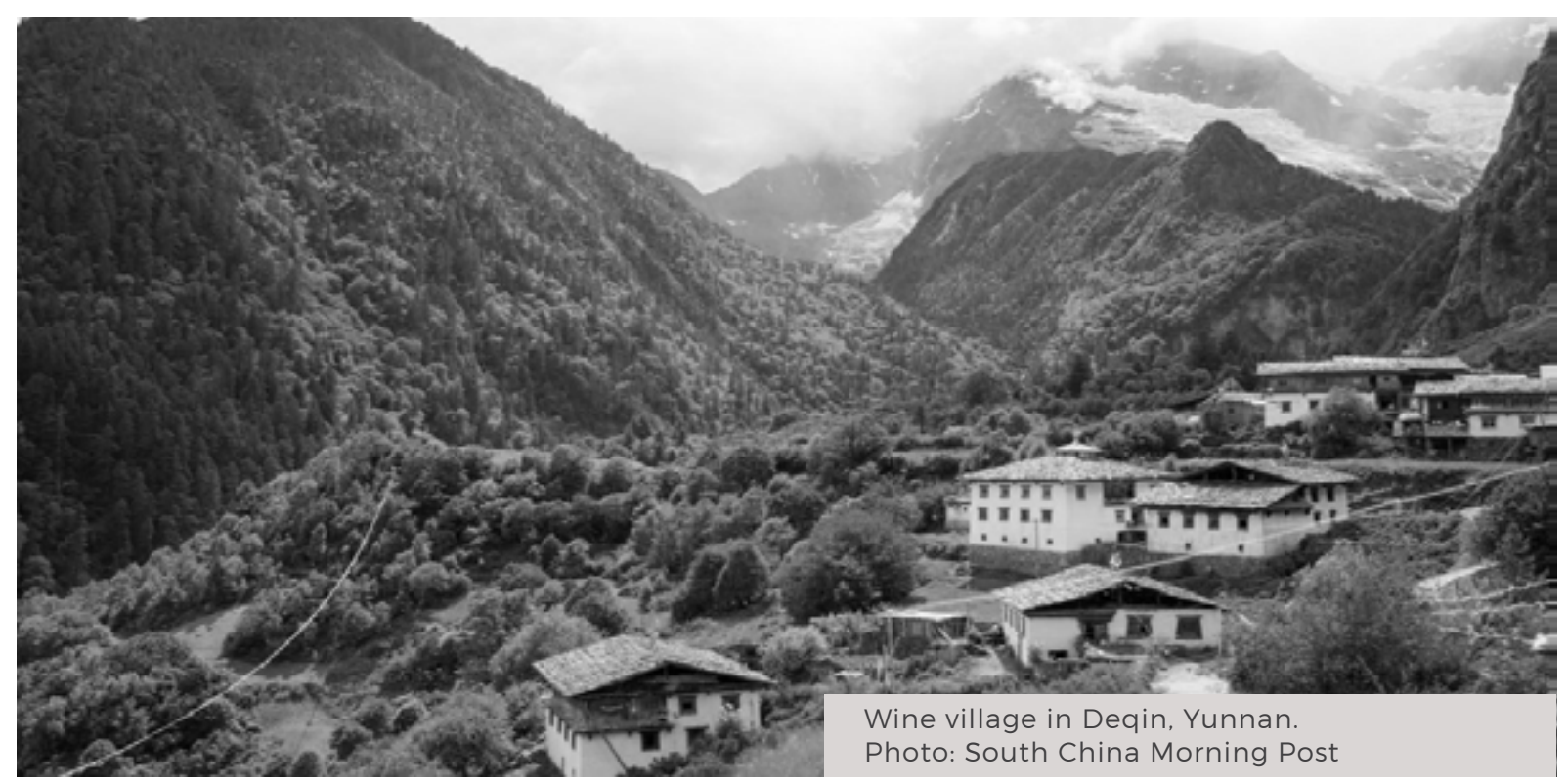

\section{Protecting Sacred Commons:}

\section{Balancing Commodity Viticulture Economies with Ecological Health in Shangri-La}

\section{Brendan A. Galipeau}

This essay explores a particular kind of local viticulture in Tibetan communities in northwest Yunnan province. While mainstream wineries emphasise modernity at any cost without much concern for the environment, the rural Tibetan grape growers examined in this article pursue an ecologically-friendly agenda meant to protect 'common' sacred landscapes. Reasons for this choice include observations of chemical degradation of the land, Buddhist ethics, and new conceptions of how ethnic representation can be exemplified by more ecologically-friendly forms of commodity production.
This essay explores a particular kind of local viticulture in Tibetan communities in China, which is different from mainstream wine industries within the larger Shangri-La area in northwest Yunnan province. While mainstream wineries are based on historical recreations of past missionary work and regional identities, and adopt narratives that emphasise modernity at any cost without much concern for the environment, the rural Tibetan grape growers whom I examine in this article pursue an ecologically friendly agenda meant to protect 'common' sacred landscapes. Reasons for this choice include observations of chemical degradation of the land, Buddhist ethics, and new conceptions of how ethnic representation can be exemplified by more ecologically friendly forms of commodity production. Recognition of these problems is meant to create what some villagers call a 'real Shangri-La or Shambala', that is a place of divine serenity in Tibetan Buddhism.

While government incentives aimed at supporting an emerging wine industry in Shangri-La through the promotion of new forms of agriculture and commodity schemes for growing grapes have tended to overlook ecological health and sustainability, awareness of such issues can be found among villagers. In some cases, these new state- 
based schemes are altered and challenged at the grassroots to promote ecologically sound practices and healthy living meant to protect common landscapes and resources. In Deqin county, the area where I carried out my research, some individuals interested in sustainability and ecological health further adapted viticulture and wine to indigenous cosmologies to protect common sacred lands, which they view as belonging to everyone and worthy of preservation.

Though wine from Deqin county has been marketed as 'natural', 'green', and 'ecological', the emergence of this industry has actually led to widespread use of agricultural chemicals introduced by wine companies and government officials, the effects of which are not lost on local communities. To understand how villagers perceive these changes, in what follows I will analyse how they have developed their own understandings of concepts such as 'organic' and 'ecological', and how these have been influenced by their Buddhist beliefs and their interest in preserving common sacred space.

I will tell this story through the eyes of Ani Dom, one individual in Deqin county who has become recognised locally and even nationally for his environmental and community work. Given both its local and transnational environmental and religious significance as the home of Khawa Karpo, one of the most sacred mountains in Tibetan Buddhism, Deqin has produced many local environmental activists interested in preserving local cultures and ecosystems. Among them, Ani Dom from Bu Village, the site of a major winery, has dedicated particular attention to viticulture. Over my two years in the field between 2014 and 2016, I visited him and lived in his village on multiple occasions.

\section{Of Sacred Mountains, Buddhism, and Chemicals}

I first met Ani Dom in 2014, shortly after arriving in $\mathrm{Bu}$ village. I planned to remain in the village for an extended period of time as it was the site of a large winery and a base for the production of sweet ice wine. On the day of my arrival, after my field assistant and I had made ourselves comfortable in a village home and were chatting with our host there, Ani Dom, an extremely talkative elderly man in a wide-brim hat with a beautiful stand of Tibetan prayer beads (mala) in his hand, appeared and explained that he had heard that a foreign visitor had arrived in the village. At that time and during many subsequent visits, I would listen to him talk about the region, the sacred mountain Khawa Karpo, Buddhism, the forest, his previous life as a hunter, and the horrible pollution that was occurring due to the chemicals used in viticulture.

In my days in Bu Village, Ani Dom spent much time telling me about local Buddhist practices and the cosmologies surrounding Khawa Karpo, which is the name of both the mountain and the god after which the place is named. As a Buddhist with a deep reverence for life, the mountain, and the local environment and culture, Ani Dom regularly shared his strong feelings about viticulture and what he perceived as excessive agricultural pollution that was killing the mountain, its spirit, and the surrounding sacred landscape. However, Ani had not always been a Buddhist: it took a near-death and highly spiritual experience to turn him into a believer. Before 1986, he was known throughout Deqin as a great hunter, perhaps the region's most famous according to his daughter Zhouma. That year, during a twenty-five-day sleepless trance brought on by a heart attack, he dreamed that the spirits of all the animals that he had killed had come back to exact revenge on him. In that vision, the god Khawa Karpo came to his rescue, and he then decided to devote the rest of his life to the preservation of the area. The god told him to throw his hunting dog in the riverwhich he did-and he also turned in his gun to the police.

Today Ani Dom's life is quite different, 
a matter of unending concern for his own family members and many other villagers in $\mathrm{Bu}$, including the village leaders, who find him a nuisance for interfering in their economic activities in the wine industry. As the village chief explained to me, he really does not get along with Ani Dom due to his resistance against wine companies and their chemicals. As leader of the community, the chief is primarily concerned with income and livelihood, so he does not see anything wrong with the current practices of the wine industry.

\section{A Mini-Environmental Movement in the Making}

Today Ani Dom devotes all of his time to working with both international and domestic NGOs to preserve Khawa Karpo and the village environment. He is perhaps best known for his work protecting a sacred old juniper grove in the village, where he has also built a small temple dedicated to the god Khawa Karpo. He was able to do this mostly thanks to funding that he personally collected through donations from NGOs and Buddhist monasteries, but the village as a community also contributed a significant amount to the enterprise. Much of Ani Dom's daily routine involves morning and evening walks to the temple to pray and perform circumbulations around it. These were the times when I would typically join him to discuss his ideas about Buddhist philosophy, conservation, and the changes brought to Deqin by viticulture and other forms of 'modernity'. He had many stories about his work with various environmental and cultural NGOs and his Buddhist teachings, and every day he had something new to share.

During my very first discussion with Ani Dom, he talked extensively about his various projects. He had recently set up a seniors' association to protect both the environment and the grape plantations-the Khawa Karpo
Traditional Knowledge and Ecological Conservation Association. One of the goals of the group was to teach villagers to plant grapes more organically and sustainably. A Hong Kong NGO sent an expert to help Ani Dom set up the organisation and provided some training on sustainable methods to grow grapes. As Ani Dom explained to me, the excessive use of pesticides for the grapes is very bad for walnuts and other fruit trees, and the soil has progressively degraded for many years. This is the reason why he is advocating for organic wine, against the wishes of his fellow villagers. In his own words:

Pesticides are harmful for the air, earth, soil, water, and all other forms of life beyond just humans. To care about these things is what traditional Buddhist philosophies teach us; all life is sacred. Before we planted grapes, our fruit and walnut trees were much healthier and now people even get skin diseases because they don't know how to properly use the pesticides.

When I asked him what he thought about Shangri-La Wine and other local wines that were promoted and marketed as natural and as part of the Tibetan culture, he replied:

Grapes and wine are not part of the traditional Tibetan culture. This culture has been lost to the chemicals and waste that come with grapes. Grapes and wine are from foreigners. The grape production here in $\mathrm{Bu}$ village is low, but our quality is good. Buddhism promotes no-killing, so we are working to pilot grapes with no pesticides for people to enjoy.

As for the future of the link between grapes and Tibetan identity in Deqin, he said: 'If the usage of pesticides continues, things will be bad and the soil will be destroyed. I don't think the grape industry is promising for Deqin's future.' 
Ani Dom's story is illustrative of a minienvironmental movement that grapes and viticulture have contributed to in Deqin. Some local people fear that most villagers in the region have fallen out of touch with Buddhism and local ecology in their pursuit of economic prosperity through chemicallyintensified grape production. Motivated by this overall concern for ecological health and Buddhist ethics, Ani Dom and a few others like him have launched their campaign against agrichemical use in viniculture. Indeed, in recent years they have worked quite actively with the Hong Kong NGO mentioned above to organise special training sessions on organic methods for grape vine care and pest management. To its credit, the NGO in its work with Ani Dom has done extensive research, even bringing experts familiar with organic methods used in Bordeaux to teach to villagers.

\section{Appeasing the Wrath of the Gods}

Ani Dom regularly portends that the pollution coming from viticulture makes the god Khawa Karpo very unhappy. Evidence of his wrath includes the retreat of the Minyong Glacier, the mountain's largest. While photo documentation shows that the glacier has been retreating for over eighty years, the rate of retreat continues to increase, which for Ani Dom is certain proof that the god is being harmed by both pollution and lack of devotion. Another example given by villagers of the dramatic consequences of failing to appease the god is a doomed attempt by Chinese and Japanese climbers to reach the summit of the mountain in 1991. Back then, an avalanche killed the entire expedition, a tragedy which was interpreted by local villagers as the response of the god Khawa Karpo to people trying to conquer his sacred domain.

Today, the quality of life and standard of living in Deqin are heavily driven by economic gains, more specifically by success in producing grapes. Major shifts have also taken place in the cultivation of crops such as wheat and barley, traditionally grown for subsistence and for religious and cultural practices. These are now being abandoned in exchange for more lucrative agricultural products. What is quite clear throughout Deqin, though, is that engagement with outside markets through agriculture and forest products is coming to redefine local perceptions of, and connections to, the Khawa Karpo landscape. In this context, the practices of Ani Dom and a few other villagers represent a form of resistance to these changes, an attempt to maintain a balance with Khawa Karpo and its spirit world to protect these sacred commons.

\section{Brendan A. Galipeau}

Brendan A. Galipeau is the Annette and Hugh Gragg Postdoctoral Research Fellow in Transnational Asian Studies at the Chao Center for Asian Studies at Rice University. His research interests and publications focus on the Tibetan regions of southwest China, historical and contemporary wine and viticulture, Catholic missionaries in Tibet, landscapes, and the socio-cultural impacts of hydropower development and agrochemical pollution. 


\section{WORK OF ARTS}

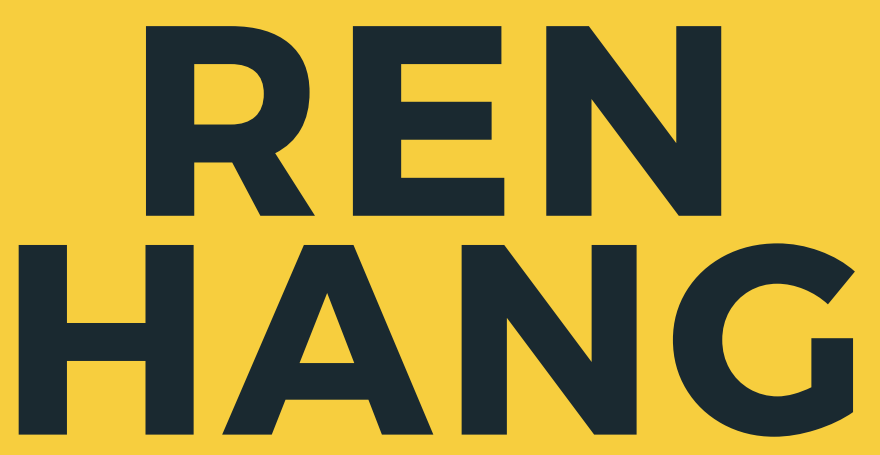

Bodies Without Redemption 


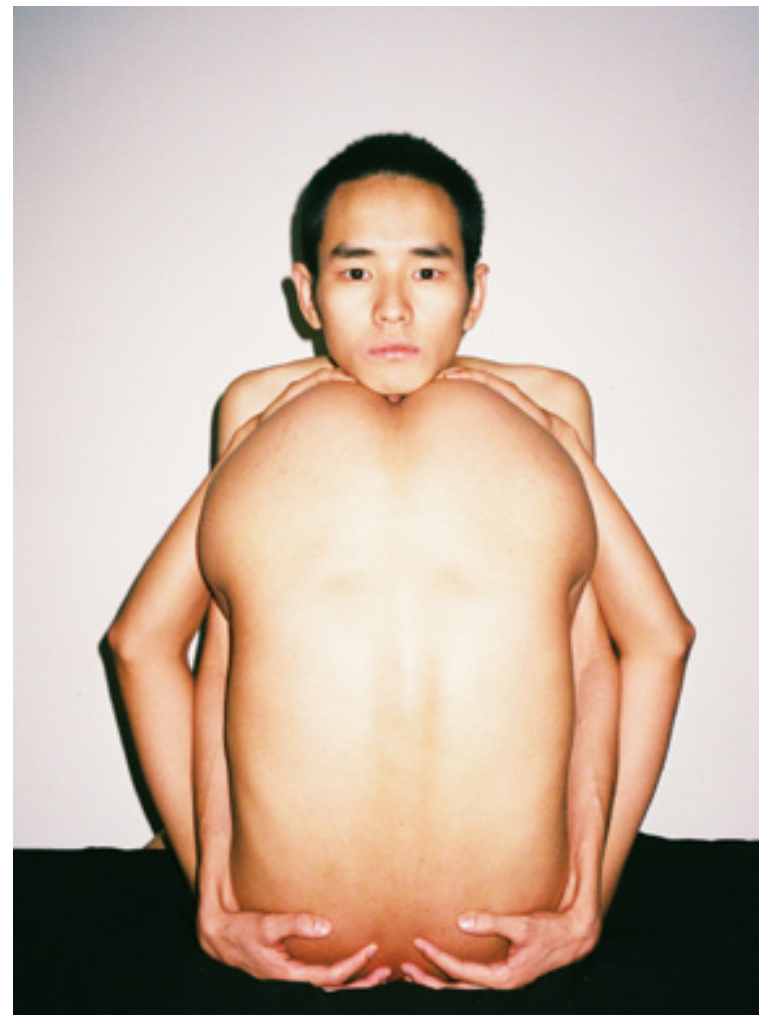

All photos in these pages are taken from Ren Hang personal website and social media.

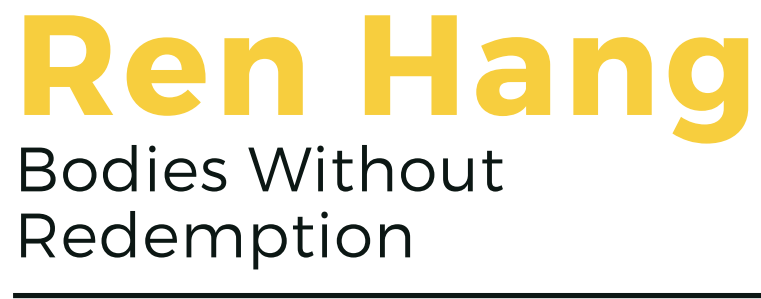

\section{Chen Shuxia}

On 24 February 2017, photographer Ren Hang leapt to his death from a twenty-eight-floor building in Beijing. He had not yet turned thirty, but his work had already attracted considerable international attention. This essay retraces the path of Ren's life, contextualising it within the rapidly developing field of Chinese photography. Beginning with the emergence of 'private photography' in China in the early 2000s, the article describes how a cultural industry made up of independent-publishing and photo fairs has blossomed in contemporary China.

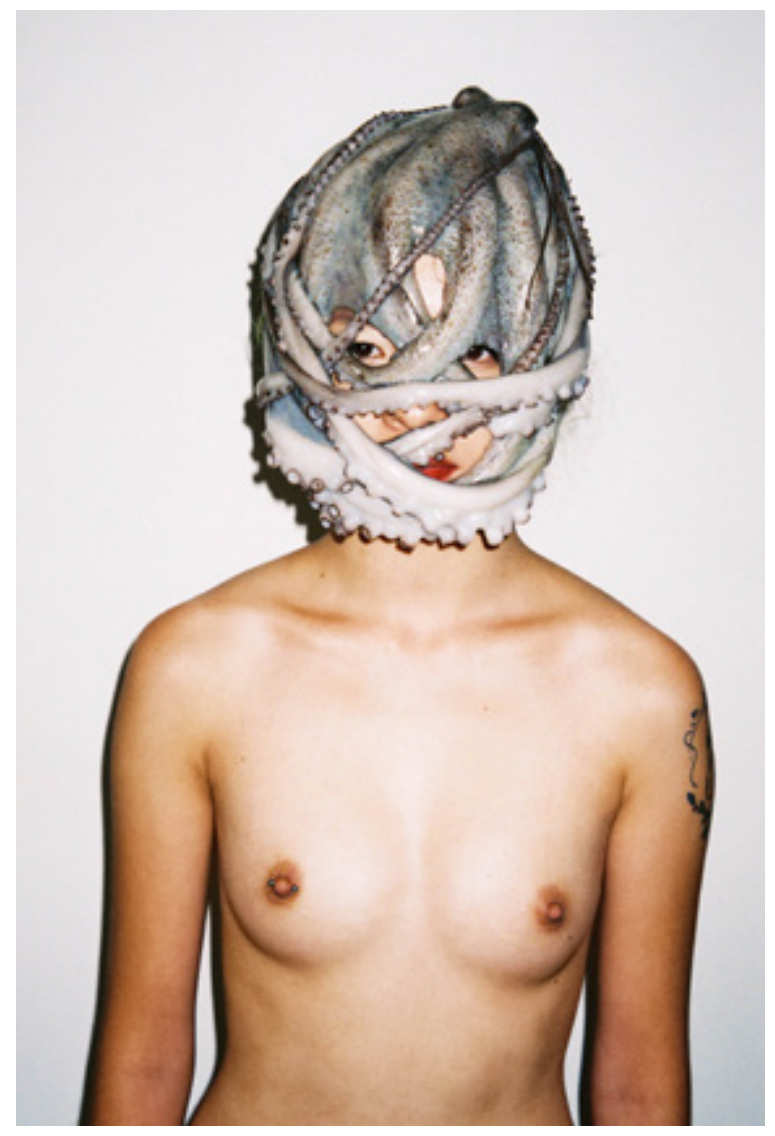

Mostly naked, friends and models of Ren Hang appear on a rooftop with skyscrapers as the backdrop, in a forest of tall trees, in a field invaded by wild grass, in a pond with budding lotuses, on a lonely rock hit by waves, or in a bathtub amongst swimming goldfish. Their naked bodies and limbs are neatly arranged as if they did not own them-an effect compounded by the deadpan expression on their young, pale faces. Labelled as 'eroticism', Ren's photography could be considered sexual, since the sexual organs of these young men and women are either subtly hidden by odd props or directly confront viewers, but Ren saw it differently. In a 2012 interview, he said: 'I don't need to try to make it classy by calling it erotica. I don't think there's anything wrong with low class.'

Ren capitalised on a 'low class' approach in his early photography. Dressed in cheap bras, fish net stockings, dyed hair, and bloody red lips, his female prototypes could have just as easily been found in Yang Yong's 
early works on Shenzhen prostitutes, such as his series 'Fancy in Tunnel' (2001-2003). However, compared to Yang's seriousness in questioning the lost identity of these female migrants when facing rapid urbanisation in south China, Ren's 'low class' seemed indifferent.

Abandoning all clothes and dyed hair, Ren's natural bodies spoke for themselves. 'We were born nude... I just photograph things in their most natural condition,' Ren explained. He said that he took up photography in 2007 , out of boredom, when he was studying advertising at a university in Beijing. With a Minolta point-and-shoot $35 \mathrm{~mm}$ film camera, Ren photographed everything around him. Dorm-mates walking around undressed in the heat of Beijing's summer became one of his early subjects.

\section{The Emergence of 'Private Photography' in China}

The trend of casually photographing the everyday life of friends started with the emergence of the so-called 'private photography' (si sheying) movement in China at the turn of the millennium. Influenced by pioneers of 'private photography' in the United States and Japan-such as Nan Goldin and Nobuyoshi Araki-young Chinese photographers, led by Lin Zhipeng (also known as No. 223) in Guangzhou, embraced the unique tone of film at the exact moment when the world was celebrating digital technology. They decided to capture the spontaneity of fleeting moments all around them, which they used to express their indifference to the rest of the world.

Ren picked up on the trend of 'private photography' a few years later. Like Lin, he declined the responsibility of social concern, but at the same time he also rejected both Yang and Lin's technique of casual composition of a photo. Ren's snapshots were carefully choreographed and framed. Mostly positioned in the middle of the image, the bodies in his photographs were always shown in uncanny twists and bends. By displaying the meaningless non-functioning bodies as props for a shot, Ren seemed to give them an alternative life. These naked young men and women looked as if they were playing hideand-seek by climbing on trees. Pinching the skin of a neck or penis seemed childishly funny. Yet the flash from the point-and-shoot camera flattened these young faces and cast a layer of stark pallor on them. Influenced by the Japanese poet, film director, and photographer Shūji Terayama, Ren created slightly strange and ghostly atmospheres. The fact that he suffered from depression, which led him to have suicidal thoughts, might also explain the absurdity and the tint of death that seeped from his images.

However, the absurd tone of his images is just right. The slender nude bodies, the young and fair faces, the out-of-context yet beautiful props form a fantasy that induces voyeuristic desire. The red lips and nails betray the 'naturalness' that Ren claimed, and hint at a formula common in fashion photography, reflecting his advertising background. If taking photographs saved him from the boredom of studying advertising, advertising came back to him in his final years. Fashion brands such as Maison Kitsuné and Gucci, as well as fashion magazines such as Purple and Libertin Dune, commissioned Ren to photograph their new collections. His stark flashed images perfectly blended 'private photography' with more staged fashion photography, giving it a brand new arty look.

\section{Photo Books and Independent Publishing}

The nudity in Ren's photos did cause some controversy. His website and exhibitions were shut down; once he was arrested while shooting outdoors. It sounds like a precarious existence, but it wasn't. In China, this is a 


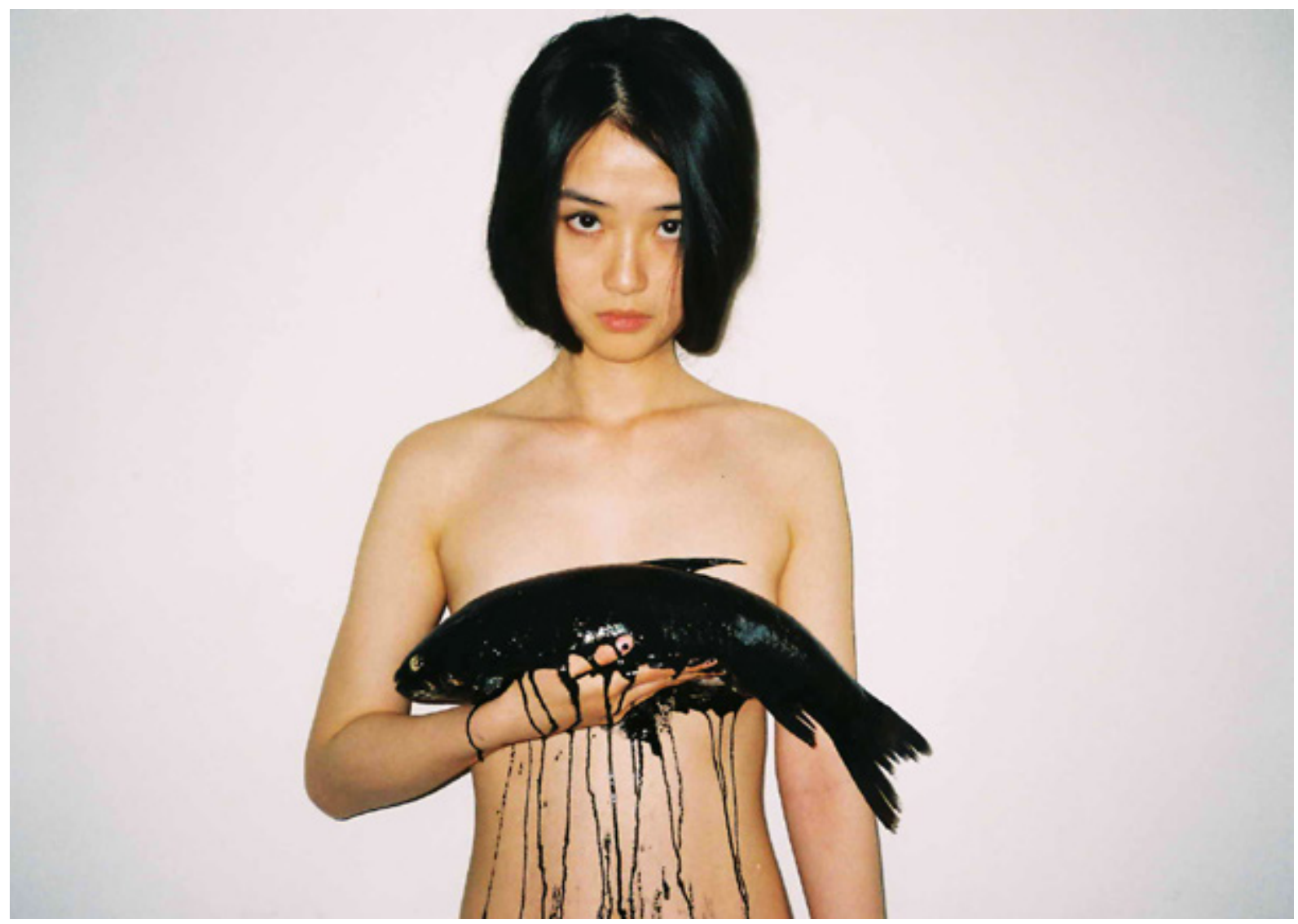

well-trodden path. He was no rebel willing to test the bottom line of the government or the extent of acceptance of a conservative society. Indeed, at the margins of contemporary China's controlled and moralised society, there remain many grey areas where legality is not enforced. While the police are intent to catch and suppress 'dissidents' aiming to mobilise disaffected populations, Ren was not one of them. He was just a self-made photographer. He publicised his photos on his website and social media accounts. He also self-published photo books. From 2011 until his death, he produced sixteen books, some of them with a print run of up to five hundred copies. People could buy them in art bookstores and online.

There are risks involved in this kind of selfpublishing in China. All books are supposed to have a formal publisher who gets an ISSN number and goes through the censorship process. Due to the fact that the censors would have probably characterised Ren's photos as obscene, most official publishers in China would have never accepted his books. They belong to an alternative world that is teeming with life and creativity, and is often enmeshed with the new economy in ways that do not make it entirely incompatible with legality.

The cultural industry occupies a prominent position within this new economy. Listed for the first time as one of the main pillar industries by the State Council in 2009, the Ministry of Finance earmarked 4.42 billion yuan of special funds for its development in 2016. This has benefited first-tier cities like Beijing, Shanghai, and Shenzhen. For example, Shenzhen has become an important base for China's cultural exports, with the value of its cultural and creative industry in 2016 estimated at 194.97 billion yuan and an annual growth rate of eleven percent. The Shenzhen municipal government is also the 


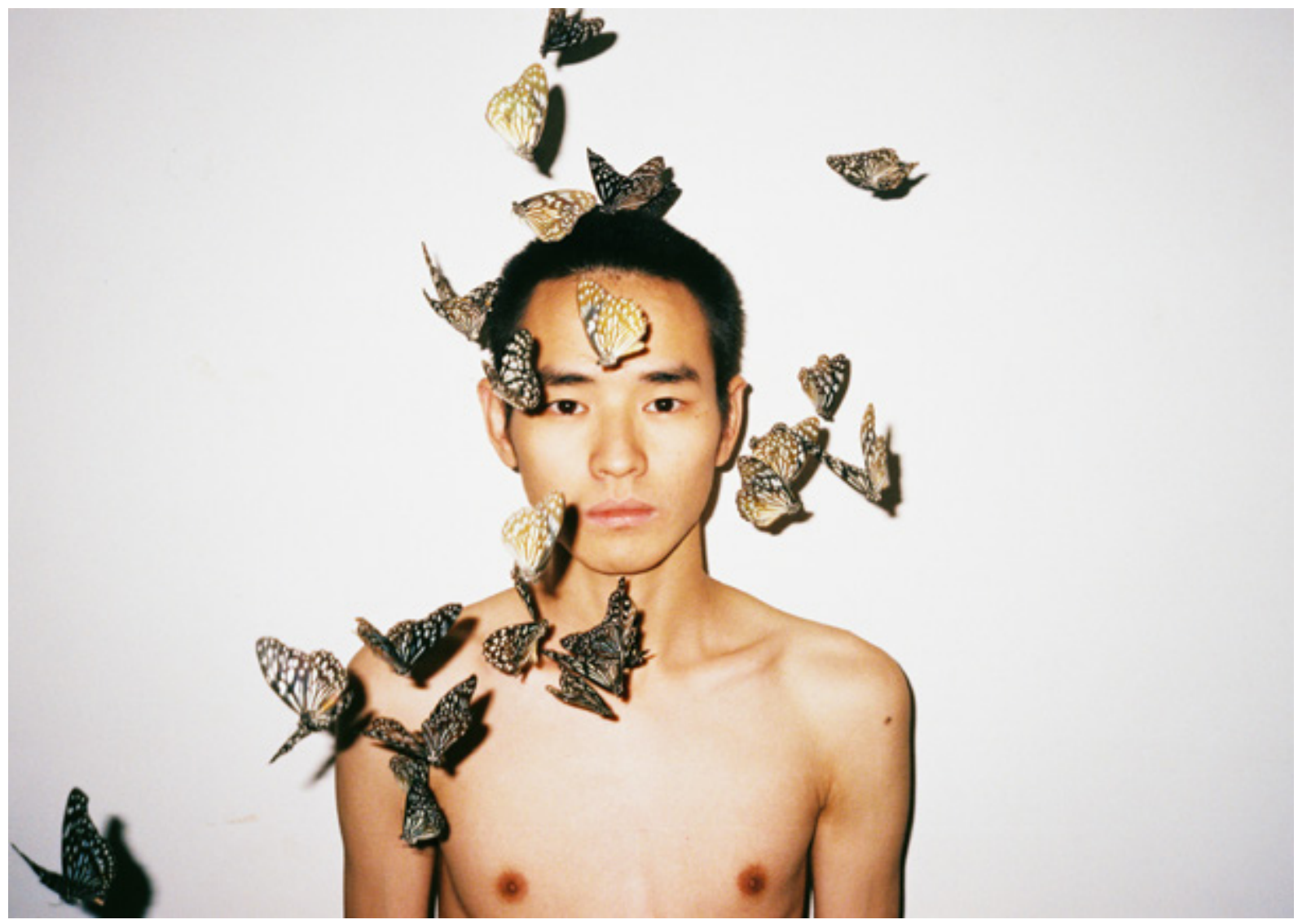

main supporter of alternative art festivals, such as the Fringe Festival and Here is Zine, Here is Shenzhen.

Zines, short for 'magazine' or 'fanzine', are a small-run self-published medium, motivated by the need for self-expression rather than profit. Today's zines all around the world have put on a new professional and fashionable look, and have gradually attracted numerous young fans even in China. Just as Su Fei and Guan Wei, owners of the first Chinese zine store BananaFish, explained: '[what we do] expresses a normal state and expectation of young people in China today...The idea of independent publishing's "speaking out for oneself"' touches us.'

The photographs, poems, and diaries about his depression that Ren Hang published on his website perfectly espouse the unique spirit of zines. The fact that they come out in limited editions also gives zines some aura of hipness. 'Their freewill, extraordinariness, the feeling of sensibly fashionable exude some charm,' said Eriko Obayashi, owner of POP Tame, a zine bookstore and art gallery in Tokyo. In recent years, self-publishing photo-books has become part of this zine frenzy in China. In a time when every urban youth has a phone and is obsessed with sharing pictures of his or her life online, photography is possibly the most accessible and appropriate medium for zines. Photo-books now can be found online, in book stores, and especially in exhibitions, photo festivals, and photo fairs.

\section{From Shenzhen to the World}

Ren Hang caught the wave of this rising hipness. While traditional publishing venues shut their doors, independent publishers at home and abroad welcomed his new brand of talent. Self-publishing enabled him to 
have a specific public, more control over the printing process, and complete freedom in the selection of content. Beginning in Shenzhen, this trend of independent publishing has gradually spread to the rest of China. It seems ironic that the not-so-legal self-publishing is a growing part of the new economy that is being promoted by the Chinese authorities. However, in today's China there exists more flexibility and freedom to meet new consumer demands in the cultural industry. Most importantly, by promoting relatively niche industries, as the Shenzhen government is doing, the Chinese authorities are able to project an open and inclusive image on the international stage, thus promoting Chinese soft power across the world.

If Shenzhen leads the way with fringe festivals and zine fairs in China, Shanghai is on the frontline of photography. Besides the establishment of the Shanghai Centre of Photography in 2015, Shanghai held its third Photofairs Shanghai in September 2016,

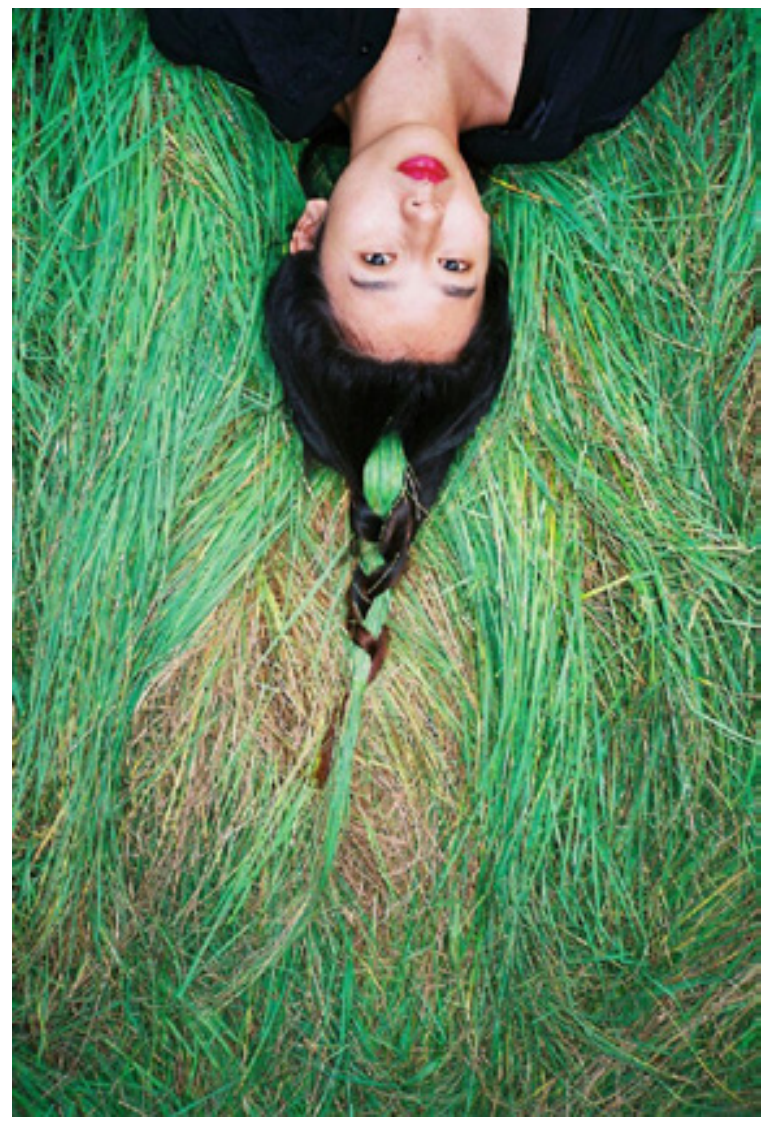

welcoming twenty-seven thousand visitors. More and more Chinese collectors are turning to photography due to the accessible price of works in limited-edition. 'The market in China has greatly matured,' said Alexander Montague-Sparey, the Artistic Director of Photofairs Shanghai, 'and this has enabled us to present exciting, emerging artists from China and across the Asia-Pacific region.' Ren Hang was exactly this type of exciting new artist. Although there is no report of his photos being sold at the fair in Shanghai, his works are highly prized among young photographers in China. Having been shown in more than twenty solo and seventy group exhibitions around the world, Ren's art moved from gallery walls to museum walls-his two latest solos 'Naked/Nude' and 'HUMAN LOVE' were launched earlier this year at the FOAM Museum in Amsterdam and Fotografiska Museum in Stockholm, two of the most important photo museums in Europe.

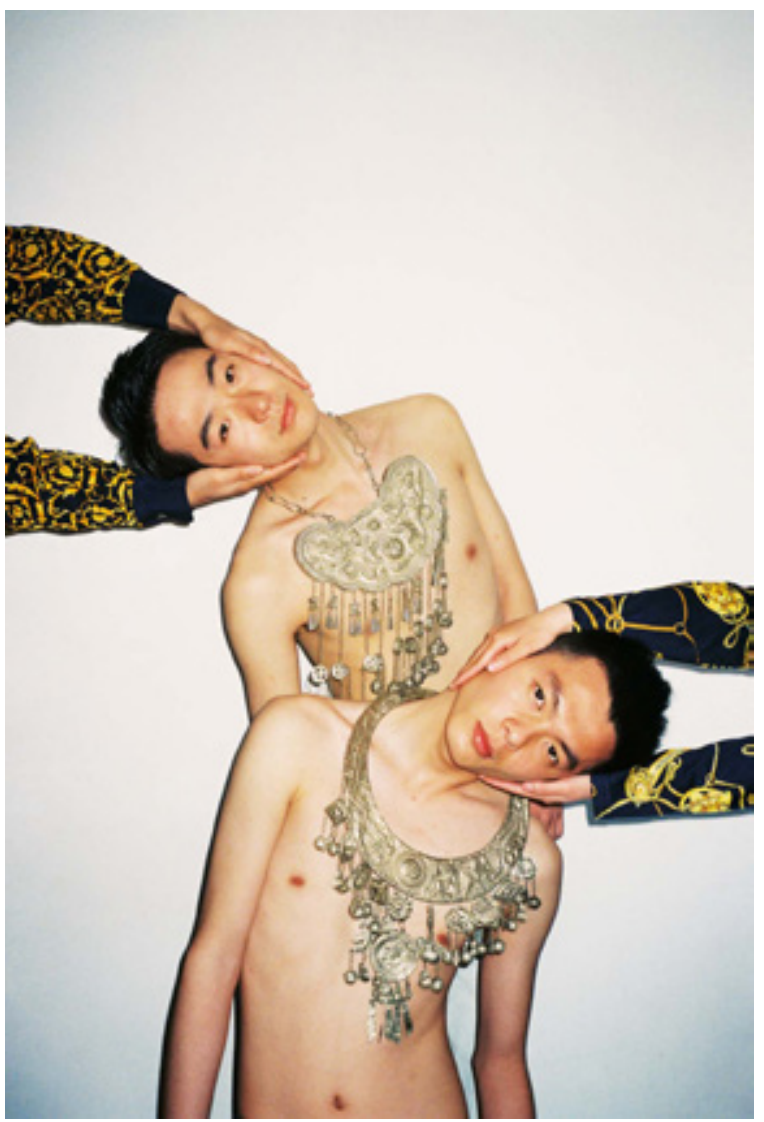


More and more young talents like Ren Hang have emerged in the last decade in China. A lot of these emerging photographers were educated in America or Europe, and are accustomed to a jetsetter lifestyle, flying between international cities for their life and work. Meanwhile, thanks to the growing domestic interest in photography, international photography festivals are mushrooming across China-such as the Pingyao International Photography Festival, the Lianzhou International Photo Festival, the China Lishui International Festival, Photo Beijing, the Caochangdi PhotoSpring, the Jimei $x$ Arles International Photo Festival, etc.-each one of them attracting thousands of photo enthusiasts from home and abroad.

Ren Hang's works have attracted more attention overseas than in his home country. In February this year, Taschen published Ren Hang's first and only international collection, which covers the work of his entire career. 'The images are fresh, but also empty

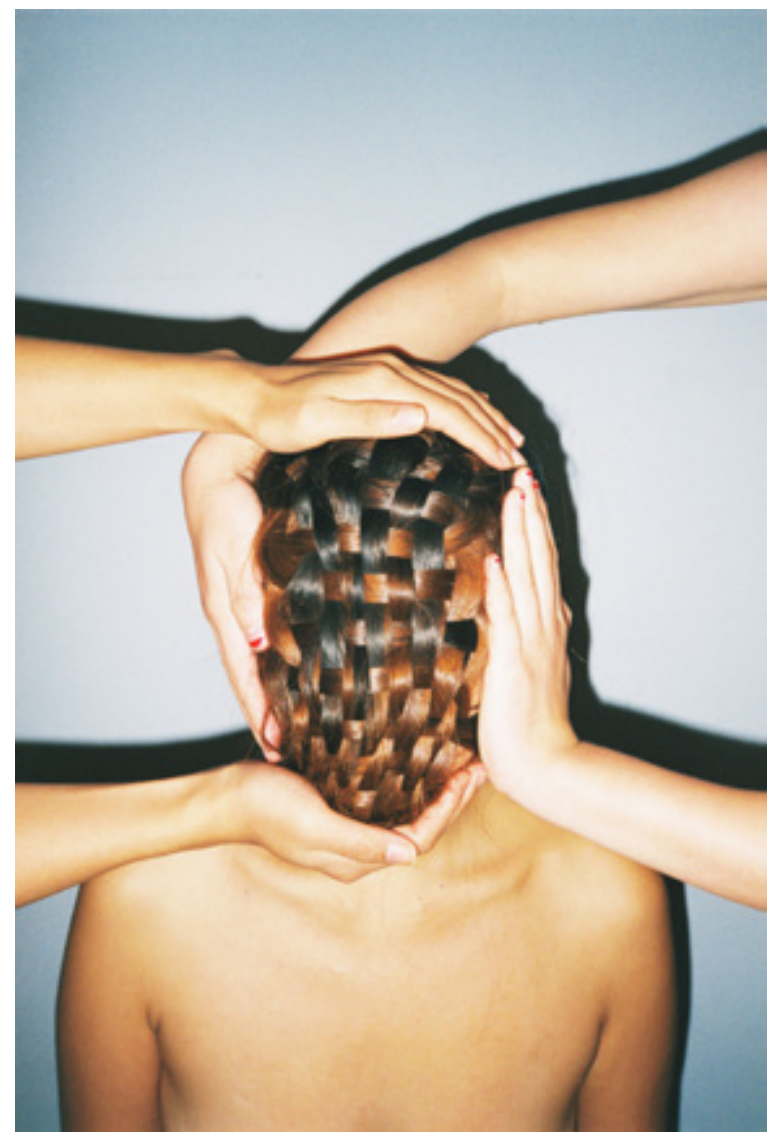

and superficial. They contain a deep sadness within,' commented Ai Weiwei. Producing these superficial yet beautiful images with objectified young bodies might have slightly alleviated Ren's deep internal sadness. In various interviews, he remarked about the pleasure he found while taking photographs, saying that it gave him a strong sense of existence. Ren actively fought his depression, but his condition made him full of despair. In one of his final posts on Weibo on 27 January 2017-on the eve of the Chinese New Yearhe said: 'Every year my wish is always the same: to die earlier.' On 24 February 2017, Ren leapt off a twenty-eight-floor building in Beijing, leaving behind his photos, his depression, a roaring fame, and the limelight of China's buzzing creative industry. He had not yet turned thirty.

\section{Chen Shuxia}

Chen Shuxia is a PhD candidate at the Australian National University. Her research focuses on Chinese photography and its aesthetic transformation in the 1980s. Shuxia's essays have been published in Trans Asia Photography Review, Art China, and artforum.com.cn. In 2014 she was a grantee of the Robert H. N. Ho Family Foundation Greater China Curatorial Residency Programme. 


\section{ACADEMIC WATCH}

\section{Shaken Authority: China's Communist Party and the 2008 Sichuan Earthquake}

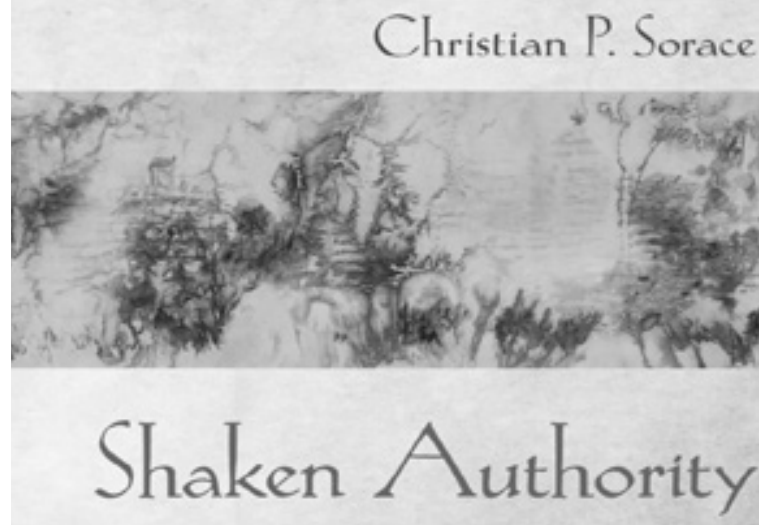

China's Communist Party and the 2008 Sichuan Earthquake

Claiming sixty-nine thousand victims, the earthquake that hit Sichuan province on 12 May 2008 not only took an enormous toll in human lives, but also had a major political impact in China. In his new book, Shaken Authority: China's Communist Party and the 2008 Sichuan Earthquake (Cornell University Press, 2017), Christian Sorace examines the political mechanisms at work in the aftermath of the tragedy. For this Academic Watch, we spoke with the author.

One of the most striking features of the aftermath of the Sichuan earthquake was the extraordinary showing of solidarity from Chinese and international civil society. In light of this, several scholars have hailed this event as a watershed for the relationship between state and society in China. Do you agree with this view?
CHRISTIAN SORACE: In the immediate post-quake aftermath, the unprecedented outpouring of compassion and volunteerism, the sudden rise of NGOs, and the open media coverage appeared to mark the long anticipated emergence of civil society in China. In hindsight, the momentary loosening of control appears to have been a mirage rather than a permanent reconfiguration of the relationship between the Chinese Communist Party (CCP) and the people. The rebuilding of Sichuan was a showcase of Party legitimacy and not a platform for expanded civic participation. My book is about this top-down process and its effects on people's everyday lives. I argue that the 'emergence of civil society' hypothesis was wrong on empirical grounds-a fact confirmed by the rise of Xi Jinping and the intensification of traditional Party methods of control. Conceptually speaking, I am also uncomfortable with this kind of research question. A researcher who sets out 'in search of civil society' may miss out on other dynamics and relationships of power that are visible without being recognisable. It is like the childhood book Where's Waldo? The obsession with finding Waldo overshadows the intricate worlds happening around him. Especially in my field of political science, the so-called objective questions and debates are so deeply normative-it is somewhat astonishing. Why is China's authoritarian regime 'resilient'? When will it 'collapse?' Why hasn't it 'collapsed'? Why hasn't 'civil society' emerged? As if 'civil society' was/is simply waiting for its moment to emerge.

With reference to the title of your book, did the earthquake actually shake the authority of the Party in the areas hit by the disaster?

CS: Many of the earthquake survivors were angry with the Party's reconstruction effort, but how do we interpret that anger? One of the things that surprised me was how high people's expectations were for the 
CCP and state to provide them with support. Sichuan earthquake survivors demanded state provision of immediate relief, housing, and long-term economic security. These expectations were conditioned by post-quake propaganda, a history of Communist Party discourse, and engrained assumptions about state responsibility. My interviewees did not complain about the Party's intervention into their lives; rather, they were disappointed and angry about the Party's failed promises. One of the problems with the state-civil society paradigm is that it is premised on state-phobic assumptions that are not generally held by ordinary citizens in Chinapeople may be exhausted and fed up with the Party's behaviour but recognise a need for its involvement in their lives. There was a politically incorrect joke circulating on China's social media platforms while I was conducting fieldwork: 'Many people actually view the government as their boyfriend: (1) Why don't you pay attention to me? (2) Who needs you to pay attention to me? (3) You owe me an explanation! (4) I don't need to hear your explanations. They are all lies!'

One of the most original aspects of your book is the attention that you pay to CCP ideas and discourse, which are usually discarded as mere propaganda. Why do you think it is important to listen to what the Party says in China today?

CS: The CCP has an extensive political vocabulary and set of concepts through which it understands the world. I take seriously Communist Party concepts like 'formalism' (xingshizhuyi), and conceptually grounded practices such as 'investigation' (diaoyan) and the 'mass-line' (qunzhong luxian), as conduits for understanding China's political and social dynamics. We should not forget that China's political system is based on a dialectical model that attempts to integrate theory (lilun) and practice (shijian), spiritual (jingshen) and material (wuzhi) development, and that the CCP considers itself a 'learning party' (xuexi dang) which is continually evolving and adapting to changing global and domestic contradictions (maodun). The CCP's epistemological foundations shape how China's political leaders act on the global stage, respond to domestic crises such as the 2008 Sichuan earthquake, and govern on a day-to-day basis. If the CCP itself takes seriously language as a field of power and control, on what grounds can we dismiss it as empty propaganda?

Among all the people you interviewed for your book, can you recall any encounter that left a mark on you?

CS: As a rule I never asked people about their personal traumas, but some people would inevitably want to discuss them. I had one conversation with a father who described to me in such vivid detail how he lost his wife and daughter during the earthquake. I couldn't maintain the pretence of professionalism and continue the interview. We cried together, hugged, smoked cigarettes, and sat there in silence. That was probably the moment that I felt most painfully the ethical dilemmas of representation-of being a foreign academic, mining the ruins of other people's lives for stories that will go in a book that will be the foundation of my academic career. One unforgettable image is the photograph of then Mianzhu county Party Secretary Jiang Guohua kneeling in front of a crowd angry parents who were marching to Sichuan's capital Chengdu to protest the death of their children. This image of a Party official on his knees pleading with the people reveals a different dimension of power and state-society relations at work in China. It does not map onto the facile dichotomies of authoritarianism and democracy (or resilience/collapse paradigms) but indexes a complicated and fraught relationship between state morality and popular sovereignty at the basis of Communist Party rule. 


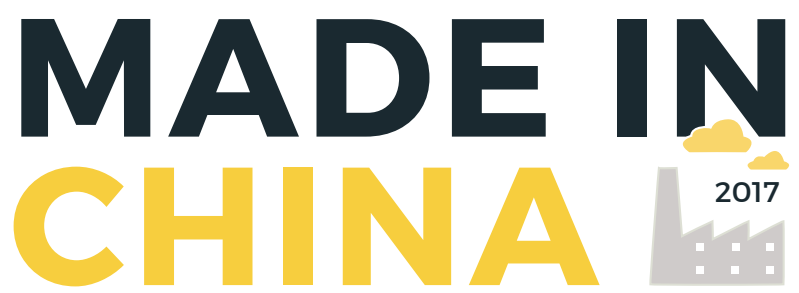

A Quarterly on Chinese Labour, Civil Society, and Rights

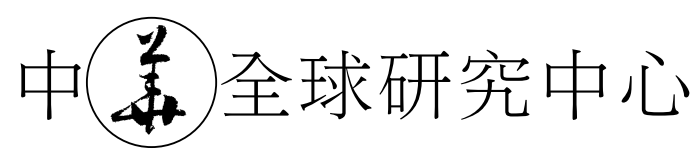

AUSTRALIAN CENTRE ON

CHINA IN THE WORLD

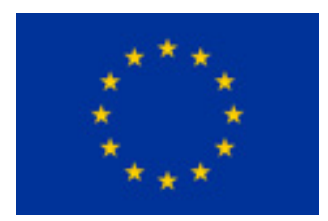

CHIN OSRIRESIE

mismatched shards of China 


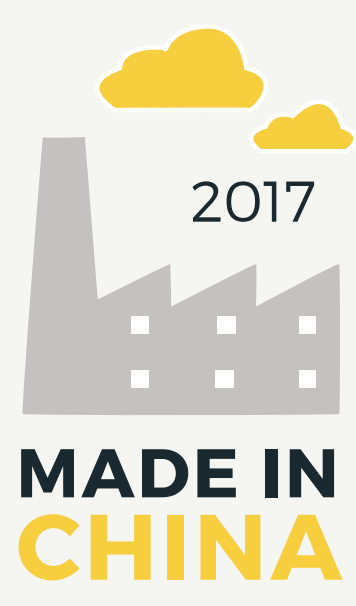

